\title{
Partes no signatarias del convenio arbitral: entre la realidad económica y la ficción jurídica
}

\author{
Hugo García Larriva*
}

\begin{abstract}
Sumario
1. Acercamiento a la Problemática. 2. Origen contractual del arbitraje. 2.1 El convenio arbitral. 2.2 Aproximación al convenio arbitral en la legislación ecuatoriana. 2.3 La forma escrita del convenio arbitral. 3. Consecuencia negocial del arbitraje: la relatividad de los efectos frente a los terceros. 4. Acercamiento a una delimitación de las partes negociales. 5. Extensión de los efectos del convenio arbitral a terceros: inferencia de la voluntad. 6 . Extensión de los efectos del convenio arbitral a terceros: el principio de buena fe. 7. Extensión de los efectos del convenio arbitral a terceros: aproximación a las aplicaciones concretas. 7.1 El grupo de sociedades. 7.2 Incorporación por referencia. 7.3 Asunción de obligaciones (Assumption). 7.4 Relación de Agencia (Agency). 7.5 Razgamiento del velo societario o teoría del alter ego. 7.6 Doctrina de los actos propios (Estoppel). 7.7 Cesión de derechos y obligaciones y de posición contractual (Assigment). 7.8 Promesa por un tercero y estipulación a favor de un tercero (Third party beneficiary). 8. Extensión de los efectos del convenio arbitral a terceros: práctica ecuatoriana. 9. El convenio arbitral y los verdaderos terceros. 10. Acción de nulidad y extensión de los efectos del convenio arbitral a terceros. 11. A manera de conclusión.

- Director del Centro de Arbitraje y Mediación de la Cámara de Comercio Ecuatoriano Americana AMCHAM-Quito. Ha sido Subdirector del Centro de Arbitraje y Mediación de la Cámara de Comercio de Quito y Secretario General del Centro de Arbitraje y Mediación de la Universidad San Francisco de Quito (USFQ). Profesor titular de las citedras de Derecho Sucesorio, Negociación y Procesos Arbitrales en la USFQ. Abogado de los tribunales de la Republica del Ecuador (USFQ), Especialista Superior en Derecho Procesal (Universidad Andina Simón Bolivar) y candidato a Máster en Derecho de Empresa por la USFQ.
\end{abstract}


Partes no signatarias del convenio arbitral: entre la renlidad cconómica y in ficción juridica

\section{Acercamiento a la problemática}

El arbitraje, desde su surgimiento como un derecho fundamental de los ciudadanos', ha revestido inusual importancia como institución del derecho, llegando a ser objeto de múltiples estudios y reflexiones de orden académico. Y es que esto no es de asombro ni extrañez, pues, desde los albores del gremialismo comercial en la alta edad media, eran los propios comerciantes quienes, ante la ausencia de un Estado nacional que ejercite un monopolio legítimo de la fuerza dentro de un orden jurisdiccional, procuraban el advenimiento de soluciones justas y equitativas a sus disputas comerciales. Solo con el surgimiento del Estado nación y su correspondiente monopolio en la administración de justicia es que se comienza a mirar al arbitraje como un método alternativo -no natural- para que los individuos resuelvan sus conflictos. Sin embargo, los fenómenos que se han desarrollado desde mediados del siglo pasado en el ámbito del comercio mundial, la globalización, el surgimiento de zonas de libre comercio y regímenes aduaneros comunes, los crecientes flujos migratorios de las inversiones, el galopante desarrollo de la tecnología, el incontrolable avance de los medios de comunicación, han exigido métodos de solución de conflictos eficientes, ágiles, transparentes, modernos, flexibles, especializados y sobre todo dinámicos ante los nuevos retos y cambios de una sociedad cada vez más pujante. Es en este contexto en el cual el arbitraje ha manifestado un crecimiento geométrico, es cada vez más preferido como una opción al acudir a la justicia ordinaria.

En la actualidad es común encontrarnos con una multiplicidad de partes, cuyos domicilios se encuentran en jurisdicciones distintas, que celebran negocios que han de surtir efectos en

1. El arbitraje nace como un derecho que parecia conectarse con aquellos denominados como fundamentales para las ciudadanos. Tales son los casos de los preceptos incorporados en las constiluciones que surgieron a fines del S. XVIII y finales del S. XIX, como la Constitución francesa del 3 de septiembre ie 1791 , en cuyo capitulo V Art, 1 numeral 5 declara que "le droit des citoyens de terminer définitivement leurs contestations par la voie de l'arbitrage, ne peut recevoir auncune atiente par les acles du pouvo ir legislatif": asi mismo es el caso del Art. $280 \mathrm{de}$ la Constilución española de 1812. que declara que "no se podra privar a ningún español del derecho de terminar sus diferencias por medio de jucces árbitros clegidos por ambas partes". 
lugares disímiles, y, como si esto no bastase, es frecuente encontrarse con la intervención de partes, sus agentes, representantes, subsidiarias, garantes, afianzadores, subcontratistas, agencias estatales, quienes intervienen de una u otra manera en la negociación, celebración, ejecución y terminación de uno, cuando no varios contratos -algunos coligados-.

Estos problemas no suscitan mayores complicaciones que las recurrentes a los mismos tratándose de las cortes nacionales, caso distinto es el del arbitraje que nos plantea retos desde su misma concepción. Si bien en el mundo podemos encontrar amplias discusiones sobre la naturaleza jurídica que reviste el arbitraje, todas reconocen el origen convencional del mismo. Es decir que el presupuesto procesal y material del arbitraje constituye necesariamente el convenio arbitral. Y esta característica, como ya se puede advertir, puede generar más de un problema, como bien lo señala Jorge SANTISTEVAN DE NORIEGA,

"si bien el origen contractual del arbitraje resulta ser un tema pacífico en la doctrina, los alcances de éste para comprometer a las partes pueden ser objeto de incertidumbre pues como veremos no siempre coinciden aquellos que suscribieron el convenio con aquellos que están comprometidos con la ejecución contractual que origina la controversia que vaya a ser sometida a arbitraje" 2 .

Imaginemos un caso hipotético en el que un sujeto " $\mathrm{A}$ " constituye un Fideicomiso inmobiliario en el cual, además de la calidad de constituyente, comparte las calidades de beneficiario y administrador del proyecto -quien emite las órdenes fiduciarias-. Como administrador instruye a la fiduciaria que contrate con la compañía " $X$ " -de la cual es propietario del $100 \%$ del paquete accionario y además es su representante legal- y responsable del diseño de los planos arquitectónicos, de ingeniería y estructurales.

2. Jorge Santistevan de Noriega, Extensión del convenio arbitral a partes no signatarias: Expresión de. la incvitabilidad del arbitraje, en Revista Peruana de Arbitraje, No. 8, Lima, 2009, p. 22. 
Concluidos los mismos, emite una nueva orden para la contratación de la misma compañía en calidad de constructora del proyecto. El proyecto preveía la instalación de algunos generadores eléctricos. " $\mathrm{A}$ " negocia con la compañía " $\mathrm{Y}$ " la provisión de los generadores en función de las especificaciones realizadas en los planos y requerimientos técnicos elaborados por " $\mathrm{X}$ ". " $\mathrm{A}$ " instruye a la fiduciaria la contratación de " $\mathrm{Y}$ " y para los efectos envía el proyecto de contrato con los términos negociados a la fiduciaria -el mencionado contrato incluye un convenio arbitral-. Durante la instalación de los generadores " $Y$ " emite instrucciones y varias correcciones técnicas para la correcta instalación de los generadores a " $Y$ ", las cuales fueron acatadas. El contrato de fideicomiso incluía una cláusula de garantía expresa por parte del constituyente-beneficiario con respecto a las obligaciones adquiridas por el mismo, además de la obligación de proporcionar al fideicomiso los fondos necesarios para la consecución del proyecto. Por varios motivos el fideicomiso resulta descapitalizado y no puede asumir sus obligaciones con el contratista " $Y$ ". Este debería demandar en arbitraje al fideicomiso -el cual ha sido descapitalizado- por el cumplimiento de sus obligaciones, pero, ¿podría demandar además a " $\mathrm{A}$ " y a " $\mathrm{X}$ " por su participación activa y determinante en la negociación, suscripción, ejecución y terminación del contrato?

Este es el tema central que nos convoca en las presentes reflexiones, ¿quiénes se encuentran obligados por el convenio arbitral?, ¿puede oponerse los efectos del convenio arbitral a personas que no lo han suscrito? En el presente ensayo trataremos de dar luces a este tema, de por sí interesante y complejo, partiendo de un análisis de la doctrina, legislación comparada, y jurisprudencia, tanto internacional como local. 


\title{
2. Origen contractual del Arbitraje
}

\author{
Como hemos enunciado, el arbitraje es esencialmente \\ convencional y excepcional con respecto a la justicia ordina- \\ $\mathrm{ria}^{3}$. Es en este sentido que el arbitraje requiere la existencia \\ de un convenio arbitral válidamente celebrado entre las par- \\ tes para su eficacia. Es claro entonces que el arbitraje es un \\ producto de la autonomía de la voluntad de las partes ${ }^{4}$ evi- \\ denciada en el convenio arbitral. Como establece Mrriam \\ Castro Salcedo
}

"[el arbitraje] nace de un negocio jurídico que como tal, proviene de la libre expresión de la voluntad de las partes vinculadas por el pacto arbitral. Sin embargo por medio del contrato de arbitraje las partes invisten de jurisdicción a per-

3. Ibidem. P. 22.

4. Cabe mencionar que la autonomia de ta voiuntad de las partes en ningún sentido es absoluta. Es más, frecuentemente ha sido limitada y matizada con otros principios como el de la buena fe negocial -y sus derivaciones- y en amplio sensu el orden público. Estas limitaciones a la autonomia de la voluntad surgen principaimente por dos motivos que según G. OsPina Y E. OSPINA - GUillerso Ospina Fernandez: Enuardo Ospina Acosta, Teoria General del Contrato y del Negocio Juridico, Ed. Temis, 6ta. cdición, Bogotá, 2000. Pp. II y 12-corresponden, cn primer lugar, a la afirmación del poder activo del Derecho y la subordinación de los individuos y de sus actividades a los dictados de un orden público, que han determinado la aparición de una copiosa legislación de caricter imperativo que, en general, disminuye las posibilidades de la autonomia de la voluntad; $y$, en segundo lugar, a las hondas conmociones sociales que han producido el cambio de las economias agrarias a indus. triales, y de cstas a una cconomia de empresa, lo que ha determinado la necesidad de que el Estado intervenga en la propia órbita de la autonomia de la voluntad privada, en detrimento de la libertad antes reconocida con generosidad a los individuos, para modificar la naturaleza, el alcance, las condiciones y las modalidades de sus negocios juridicos y de los efectos que esios están lamados a producir. En este sentido, y como sostiene J. C. Garibotto - Juan Cartos Garinotto, Teoria Genctal del Acto Juridico, Ed. Depalma, Buenos Aircs, Argentina, 1991., p. 22-, la autonomia asi concebida no es admitida de manera absoluta, sino sólo como un principio, con las limitaciones que impone la ley de modo imperativo, puesto que es menester para el ordenamiento juridico la armonización de los intereses privados con los derechos $\mathrm{c}$ intereses de terecros asi como con los de la comunidad. Para luis Parraguez - Luis Sergio Parraguez Ruiz, Cuato Bomador del Manual de Negocio Jutidico, USFQ Inédito, 2008, pp. 20, 21.- existen varios factores que limitan la libertad, que en amplio scnsu se concedia a los particulares, entre éstos identifica unos especificos, como el equilibrio contractual, la teoria de la imprevision, actos propios, buena fe, y otro de manera mis amplia, el orden público, en el que se comprenden el interés general de la sociedad, y en el que encuentran acogida tanto las exigencias y prohibiciones que expone la key, como los requerimientos de la moral y las buenas costumbres. Es esie reconocimiento de la naturaleza propia de la libertad del hombre de actuar y reglar sus actuaciones, lo que nos permiten a los particulares, como la solución más lógica, dirimir las controversias dentro de nuestra misma esfera de intereses. Es esta autonomia privada la que nos permite acudir voluntariamente, como requisito de la LEY DE ARBITRAE Y MEDIAción (LAM) - Codificación de la ley de arbitraje y mediación, Registro Oficial $\mathrm{N}^{\circ} 417$, Jueves 14 de diciembre del $2006-$, a causa de árbitros, por medio de un negocio juridico tipico de naturaleza auténtica que se denomina convenio arbitral. 
Partes no signalarias del convenio arbitral:

entre in realidad cconómica y In ficción juridicn

sonas privadas con el fin de que decidan definitivamente un conflicto que los involucra". 5

\subsection{El convenio arbitral 6}

El convenio arbitral puede ser definido, según palabras de L. F. REGLero CAMPOS, como "el instrumento en que se plasma el derecho de las personas a solucionar las cuestiones litigiosas de su libre disposición"7, es decir que las partes renuncian a su derecho a acudir ante la jurisdicción ordinaria, acordando someter sus conflictos a una jurisdicción que la ejercen unos terceros privados.

Otra definición es la que nos aporta P. AYLWIN AZOCAR ${ }^{8}$, el cual sostiene que con este concepto genérico nos referimos al acuerdo de voluntades que dentro de los arbitrajes de carácter voluntario debe darse como presupuesto previo para el mismo. Para GonzÁlez de COSSIO, "el acuerdo arbitral es un contrato por virtud del cual dos o más partes acuerdan que una controversia, ya sea presente o futura, se resolverá mediante arbitraje"9. Es en este acuerdo donde las partes otorgan competencia a los árbitros para que diriman sus controversias. Para F. CoRdón MORENO ${ }^{10}$ el convenio arbitral también es la fuente ordinaria del arbitraje voluntario, aunque admite que excepcionalmente puede ser el testamento"1.

5. Myriam Castro Salcedo, El contrato de arbitrajc, Ed. Legis, Bogotá, 2005, p. 114.

6. En el presente ensayo no se hará un análisis exhaustivo del convenio arbitral, sino en cuanto sea relevante para el tema a tratar, por lo cual dejaremos por fuera o toparemos de manera superficial temas muy apasionantes.

7. L. Fernando Reglero Casiros, El arbitrajc, Ed. Montecorvo, Madrid, 1991, p. 65.

8. Cfr. Ibidem, p. 189.

9. Francisco Gonzillez de Cossio, Arbitrajc, Ed. Pornua, México, 2004. p. 56.

10. Cfr. F. Condón Moreno, El Arbitraje..., p. 57.

11. No compartimos el criterio del autor puesto que el convenio arbitral es independiente del negocio en donde se encuentre, y sera éste -el convenio arbitral-siempre la fuente del arbitraje, más allá que se halle estipulado en un negocio juridico determinado. El que nos refiramos a arbitrajc testamentario - contenido en un testamento- a estatutario - contenido en un estatuto- es una denominación para hacer referencia a la fuente donde originariamente se halla el convenio arbitral. 
Un efecto, mas no elemento del convenio arbitral, es el llamado contrato de compromisorio o receptum arbitriii ${ }^{12}$, mediante el cual el árbitro acepta su nombramiento y se vincula de manera directa, manifestando su voluntad de ejercer las tareas de árbitro para el caso concreto; y contrae frente a las partes el deber juridico de ser su tribunal. Sin embargo, ni las facultades ni los deberes jurisdiccionales del árbitro devienen de este contrato, puesto que le impone la obligación privada para con las partes de desempeñar el cargo y le otorga el derecho de exigir de ellas un honorario; ergo, la relación privada que crea el contrato de compromisorio nada tiene que ver con la función pública que desempeña el árbitro frente a las partes.

\subsection{Aproximación al convenio arbitral en la legislación ecuatoriana}

Según el artículo 5 de la LAM "[e]l convenio arbitral es el acuerdo escrito en virtud del cual las partes deciden someter a arbitraje todas las controversias o ciertas controversias que hayan surgido o puedan surgir entre ellas respecto de una determinada relación jurídica, contractual o no contractual...". Como bien sostiene Álvaro Galindo CARDONA ${ }^{13}$, en nuestra legislación ya se superó aquella bizantina discusión sobre el compromiso arbitral, cuya obtención era casi imposible, y la cláusula compromisoria, al incluir dentro del convenio a ambos y finalmente establecer la autosuficiencia del Convenio Arbitral14.

Bajo estos parámetros, podemos decir que el convenio arbitral en nuestro ordenamiento legal es un negocio jurídico que requiere que la voluntad revista una forma escrita. Este requisito debe cumplirse tanto dentro del negocio jurídico sobre el cual

12. Cfr. P. Aylivin Azócar, El juicio.... p. 46.

13. A. Galindo Cartons, "Origen y desartollo de la Solución Alternativa de Conflictos en Ecuador", en luris Dietio, Universidad San Francisco de Quito, Colegio de Jurisprudencia, Año II, No. 4, Agosto 2001, pp. 124, 127.

14. Un interesante estudio comparativo sobre la evolución de la autosuficiencia del convenio arbitral fue realizado por Rnoue J. Caivano. Vid, Rogue J. Caivano. La Clausula Arbitral, Universidad del Rosario, Cämara de Comercio de Quilo, Bogotá, 20II, pp. I38-198. 
trata, como por documento aparte, siendo en este último caso necesario que el convenio identifique de manera inequívoca el negocio jurídico al cual hace referencia el mismo. De igual manera este requisito puede ser suplido por "el intercambio de cartas $o$ de cualquier otro medio de comunicación escrito de que deje constancia documental de la voluntad de las partes de someterse al arbitraje" 15 , de suerte que en nuestro sistema es plenamente válido un convenio arbitral epistolar, contenido en facsímiles, o cualquier otro medio de comunicación e información que permitan su consulta, verificación y acceso posterior de manera escrita, siempre y cuando no vulnere las disposiciones legales en la materia. En el caso de controversias extracontractuales, debe identificarse de la misma manera los hechos que los originan.

Un aspecto que es de suma importancia analizar es que el convenio arbitral, y en general el arbitraje en el Ecuador, tiene a su favor el principio in dubio pro arbitrii. El Art. 7 de la LAM, al referirse al evento en el cual se discuta ante juez ordinario la excepción de existencia del convenio arbitral, establece que "en caso de duda, el órgano judicial respectivo estará a favor de que las controversias sean resueltas mediante arbitraje".

\subsection{La forma escrita del convenio arbitral}

Lejos quedó ya aquella época en la cual para celebrar un convenio arbitral las partes debían acudir ante un notario acompañadas de testigos de intachable conducta y probidad notoria para celebrar una cláusula compromisoria por escritura pública -que de paso debía ser requerida judicialmente para obtener luego el compromiso arbitral-16. Las exigencias formalistas que establecían provisiones encaminadas a dificultar la celebración del convenio arbitral venían de la mano de una visión recelosa del arbitraje. Esta visión, marcada claramente por una desconfianza en el sistema arbitral, concebía al arbitraje como un meca-

15. Articulo 6 LAM.

16. Rogue J. Caivano, La Claiusula .... p. 96. 
nismo de renuncia a la jurisdicción ordinaria, o en otras palabras, un sistema de renuncia a un fuero natural de las personas, ergo, para ser eficaz, debía provenir de un convenio arbitral celebrado con el mayor grado de formalismos y ritualismos posible.

Todo esto vino acompañado de una interpretación de carácter restrictivo del arbitraje; me explico. Al ser el arbitraje sustancialmente una renuncia y excepción a la jurisdicción ordinaria, como toda renuncia, es menester interpretarla en estricto derecho de manera restrictiva -quien renuncia lo hace única y exclusivamente a aquello expresamente contemplado, sin la posibilidad de inferir por extensión la renuncia a cualquier otro tipo de derechos-. Este pensamiento afortunadamente ha sido dejado de lado, pues, como bien señala RoQue J. CAIvano,

"es correcto afirmar que la sujeción de las partes a la jurisdicción del Poder Judicial es un elemento "natural" en cualquier contrato, desde que existe sin necesidad de pacto; pero la jurisdicción arbitral, aunque sea una excepción a ello, lo es sólo en el sentido de requerir una declaración de voluntad y no en el sentido de interpretar su extensión con carácter restrictivo en los casos en que ha sido inequívocamente pactada"17.

$\mathrm{Al}$ respecto, un interesante fallo de una Cámara Comercial de Argentina estableció que

"en la medida en que la ley autoriza a los sujetos de derecho a constituir su propio juez mediante la sujeción a árbitros y que el tema del diferendo verse sobre materia patrimonial perteneciente a sujetos capaces, no se entiende por qué la competencia de la llamada 'jurisdicción arbitral' soporta la minusvalía de ser apreciada restrictivamente" 18 .

17. Ropue J. Caivano, Arbitraje y grupos de sociedades. Extension de los efectos de un acucrdo arbitral a quien no ba sido signatario. en Lima Arbitratio: Revista del Circulo Peruano de Arbitraje, No. 1, Lima, 2006, p. 157.

18. Ibidem, p. 153 
En este cambio de pensamiento y avance doctrinal, jurisprudencial y legal influyeron de manera determinante, por un lado la CONVENCIÓN DE NUEVA YoRK (CNY) ${ }^{19}$, y, por otro, los trabajos y estudios realizados por la COMISIÓN DE LAS NACIONES Unidas para el DERECho MERCANTIL InTERnacional (CNUD$\left.\mathrm{MI}^{20}\right)$. La primera sentó un tope mínimo y estándar de basamento sobre los requisitos de un convenio arbitral para su reconocimiento en otro estado, dejando a salvo el que los distintos países signatarios den un tratamiento más favorable al mismo en sus legislaciones internas, pero al menos comprometiéndose a reconocer y respetar este contenido mínimo. La segunda con la preparación de Leyes y Reglamentos Modelos -que han influenciado la redacción de gran parte de la legislación sobre la materia- y recomendaciones que son fruto de arduas sesiones de trabajo que recogen paulatinamente los avances en materia arbitral.

La CNY en su artículo II (1) establece que cada uno de los estados partes "reconocerá el acuerdo por escrito conforme al cual las partes se obliguen a someter a arbitraje todas las diferencias o ciertas diferencias que hayan surgido o puedan surgir entre ellas". Ahora bien, qué debemos entender por acuerdo escrito al amparo de la convención de Nueva York. Es evidente que en el marco de la redacción de la CNY, y luego de más de 50 años de su aplicación, el piso dejado por esta con respecto al requisito de forma del convenio arbitral, hoy por hoy, se encuentra muy alto, inclusive más rígido que la mayoría de legislaciones 21 , y que a la luz de los nuevos desarrollos de la jurisprudencia internacional la significación de "acuerdo por escrito" debe tomar un derrotero más flexible y compatible con las actuales circunstancias. El artículo II (2) establece que la expresión "acuer-

19. Convención sobre el Reconocimiento y la Ejecución de las Sentencias Arbitrales Extranjeras, Codificación 1221, Registro Oficial Suplemento 153 de 25 de noviembre de 2005.

20. También conocida por sus siglas en Inglés UNCITRAL - United Nations Commission on Intcrnational Trade Law.

21. ALBFKt JAN VAN DEN Berg, Hypothetical draft Convention on the International Enforcement of Arbitration Agnements and Aluands, en Arbitrajc Comercial y Arbitraje de Inversion, Tomo 2 "Convencion de Nueva York de 1958, Reconocimiento y ejecucion de sentencias arbitrales extranjeras", Instituto Peruano de Arbitraje, Lima, 2009, p. 843. 
do por escrito denotarín 22 un acuerdo arbitral contenido en un negocio firmado por las partes o en el intercambio de comunicaciones. Para dar un significado a la palabra "denotará", uno puede presumir que algunas otras formas de acuerdo arbitral pueden satisfacer el requisito formal de la convención ${ }^{23}$-verbi gracia el intercambio de mensajes de datos entre otros-. En este mismo sentido se ha pronunciado la CNUDMI al establecer que el requisito establecido en el artículo II (2) "se aplique reconociendo que las circunstancias que describe no son exhaustivas" 24 .

De igual manera que la concepción de que los hechos descritos en el artículo 2 (ii) deben considerarse como taxativos, paulatinamente se ha ido dejando de lado la idea de exigir como requisito para la validez del convenio arbitral la firma de las partes"25. Justamente la palabra "signatario" -que da lugar al presente ensayo- es una reminiscencia de aquella época en la cual se exigía que el convenio arbitral se encuentre firmado por las partes para su validez. Como se ha dicho esta idea ha sido desplazada poco a poco por las decisiones jurisprudenciales que han flexibilizado el requisito formal, tal es el caso de KAHN LuCAS LANCASTER INC V. LARK INTERNATIONAL LTD. donde la Corte de Apelaciones del Segundo Circuito de los Estados Unidos esta-

22. Del texto oficial en español de la convención. El texto original en inglés se refiere a "shall include" que a nuestro criterio es más revelador para el análisis a realizar.

23. NOAH RuBins, Arbitration agreements and non-signatories, en Arbitrajc Comercial y Arbitraje de Inversión, Tomo 2: "Comvenciön de Nueva York de 1958, Reconocimiento y ejecución de sentencias arbitrales exiranjcras", Instituto Peruano de Arbitrajc, Lima, 2009, p. 544.

24. Recomendación relativa a la interpretación del párrafo $2 \mathrm{del}$ articulo ii y del párrafo $1 \mathrm{del}$ articulo vii de la Convención sobre el Reconocimiento y la Ejecución de las Sentencias Arbitrales Extranjeras, hecha en Nucva York, el 10 de junio de 1958, aprobada por la Comisión de las Naciones Unidas para el Derecho Mercantil Internacional el 7 de julio de 2006, en su 39" periodo de sesiones, disponible en http://www.cnudci.org/pdf/spanish/texts/arbitration/NY-conv/A2S.pdf

25. En contratio Armando Sirrano Puig - Aranando Strrano Puig, La autonomia de la voluntad en el convenio arbitral, alcances y limitaciones: El caso ecuatoriano, en Tratado de Derecho Arbitral: El Convenio Arbitral. Tomo 1. Pontificia Universidad Javeriana, Grupo Editorial Jbañcz, Instituto Peruano de Arbitraje, Bogota, 2011, pp. 558, 559- cstablece que, en la legislación ecuatoriana es "necesario que el convenio arbitral conste por escrito, que se laalle firmado por las partes, que contenga su voluntad cierta y clara de someierse al arbitraje y que haya constancia documental de tal voluntad". No compartimos el crilcrio del autor, pues la única referencia que se hace a la firma de las partes es al reconocer la posibilidad de existencia de un convenio arbitral en el intercambio de comunicaciones de las partes que permitan su acceso por escrito posterior (Art. 6 LAM). Es más las expresiones "se entenderá tambièn" y "sino tambièn" que usa el mencionado articulo nos da a entender -al igual que la expresión "denotara" en la CNY- que algunas otras formas de acuerdo arbitral pueden satisfacer el requisito formal. 
Partes no signatarias del convenio arbitral:

eutre In realidad económica y la ficción juridica

bleció que "la convención de Nueva York no requiere que la cláusula arbitral se encuentre firmada por las partes mientras exista por escrito" 26 .

No ha sido ajena a esta tendencia las leyes modelos CNUDMI sobre arbitraje comercial. El artículo 7 (2) ${ }^{27}$ de la Ley Modelo de 1985 establecía que "se entenderá que el acuerdo es escrito cuando esté consignado en un documento firmado por las partes" o en el intercambio de comunicaciones entre las partes. Disposición que ha sido interpretada en el sentido más amplio por parte de los tribunales arbitrales ${ }^{28}$ y evita interpretaciones

26. KAIIN LuCAS LANCASTER INC v. LARK INTERNATIONAL LTT., 186 F.3d 210 (2d ci. 1999) citado en Noail RUBins, Arbitration ..., p. 543.

27. Artículo 7. Definición y forma del acuerdo de arbitrajc

1) El "acuerdo de arbitraje" es un acuerdo por el que las partes deciden someter a arbitraje todas las controversias o ciertas controversias que hayan surgido o puedan surgir entre ellas respecto de una determinada relación juridica, contractual o no contractual. El acuerdo de arbitraje podrá adoptar la forma de una cláusula compromisoria incluida en un contrato o la forma de un acuerdo independiente.

2) El acuerdo de arbitraje deberá constar por escrito. Se cntenderá que el acuerdo es cscrito cuando esté consignado en un documento firmado por las partes o en un intercambio de cartas, télex, telegramas u atros medios de telecomunicación que dejen constancia del acuerdo, $\mathrm{o}$ en un intercambio de escritos de demanda y contestación en los que la existencia de un acuerdo sea afirmada por una parte sin ser negada por otra. La referencia hecha en un contrato a un documento que conticne una cláusula compromisoria constituye acuerdo de arbitraje sicmpre que el contrato conste por escrito y la referencia implique que esa cláusula forma parte del contralo.

Disponible en http://www.uncitral.org/pdf/spanish/texts/arbitration/ml-arb/ml-arb-s.pdf

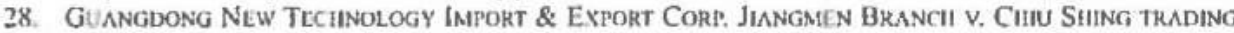
as B C. Property \& Trading Comipany, Cone Suprema de Hong Kong. 23 de agosto de 1991, Caso CLOUT 677, CLOUT 62, en este caso si bien en el contrato firmado por las partes no existia un convenio arbitral propiamente dicho, el tribunal estimó que cra competente pues el acuerdo habia sido confirmado por las partes mediante remisión a otros documentos aunque no se hallaban firmados - en estrictu sensu- por las partes. Willanm Cosirany v, Chu Kong Agency Co. LtD. and Guangziou OCenn Simpring Company, Corte Suprema de Hong Kong, 17 de febrero de 1993, Caso Clout 44. CLOUT 2, en este caso existia una nota de embarque que contenia un convenio arbitral que fue firmado únicamente por una parte, el tribunal arbitral estimó que al haber estado el convenio arbitral por escrito en la nota de embarque y al haberse ejecutado las prestaciones del contrato - la entrega de material por una parte y la aceptación del mismo por la otra-constituye consentimiento suficiente y prucba de la voluntad de las partes de arbitrar. Ciana Nationnl. Electronic Import \& Export Sianzien Company v Chol Cilik Ming (trading as ERWO Enterprist.s Company), Corte Suprema de Hong Kong, 9 de marzo de 1993. Caso CLOUT 688, CLOUT 64, en este caso se demandó en base a un precontralo y varios contratos conexos, éstos últimos se hallaban firmados por una parte y sellados por esta misma parte en vez. de la contraparte, es decir, carecian de la firma una de las partes, el tribunal arbitral estimó que al ser príctica comercial entre ellos el que una parte sellara en lugar de la firma de la contraparte, si bien no existia firma en sentido estricto de ambas partes, esto constituia consentimiento claro para arbitrar. OONC LINES Linated v. SINO-AMERICAN TRADE ADVANCEMENT Co. LTD. Corte Suprema de Hong Kong, 2 de febrero de 1994, Caso CLOUT 62, CLOUT 4, en este caso existia una póliza de fletamento que no contenia las firmas de las partes, sin embargo el tribunal consideró que diversas comunicaciones intercambiadas entre ellas proporcionaban constancia escrita suficienic de su acuerdo de someterse al arbitraje. 
restrictivas y se aleja de anquilosados formalismos y ritualismos -como la exigencia de la firma en el convenio arbitral-. Todos los tribunales arbitrales, eso sí, buscan evidencia por escrito de la existencia del convenio arbitral, pues fue claro que en las reuniones preparatorias de la Ley Modelo de 1985, si bien no se encontraban en contra de los mismos, se quiso dejar por fuera de este texto a los convenios arbitrales orales que se daba en algunos lugares y bajo ciertas prácticas comerciales ${ }^{29}$, pero fueron sumamente cautelosos al no establecer una sanción a la falta de escrituración del convenio, pues fueron más proclives a que los tribunales arbitrales decidieran su eficacia o no con respecto a las actuaciones determinantes de las partes en el caso concreto ${ }^{30}$.

Es lógico -como hemos enunciado- que el paulatino desarrollo de la jurisprudencia arbitral, a tono con las realidades económicas y comerciales cambiantes, haya flexibilizado y reducido aquellos requisitos establecidos originalmente en el texto de la CNUDMI de 1985. Todos estos avances fueron recogidos en la revisión al texto de la Ley Modelo realizado en el año 200631, dada cuenta de la ineficacia y desuso de tan estólidos y estultos requisitos por parte de los tribunales arbitrales y las cortes nacionales ${ }^{32}$. Es así como el nuevo artículo 7 de la Ley Modelo CNUDMI 2006 presenta dos opciones. La primera opción ${ }^{33}$ mantiene la expresión del requisito de escrituración del convenio arbitral, sin

29. "Acucrdos orales que han sido comunes en algunos lugares y áreas del comercio no deberian estar cobijados por la Ley Modelo, sin embargo debe dejarse abierta su regulación y reconocimiento bajo otras legislaciones", CNUDMI, Report of the Working Group on international contract practices on the work of its fifth session. 22 de febrero al 4 de marzo de 1983, New York, A/CN.9/233, p. 66.

30. Ibidem, p. 66.

31. Disponible en http:/www uncitral org/pdf/spanish/texts/arbitration/ml-arb/07-87001 Ebook.pdf

32. "Los profesionales del arbitraje han señalado que, en varias situaciones, la elaboración de un documento por escrito resulta imposible o poco práctica. En los casos en que la voluntad de las partes para someierse a arbitraje no constituye un problema. deberia reconocerse la validez lé acuerdo de arbitraje. Por ese motivo, y con miras a ajustar mejor su contenida a las prácticas contractuales internacionales, se revisó en $2006 \mathrm{cl}$ articulo 7." CNUDMI, Nota explicativa de la secretaría de la CNUDMI acerca de la Ley Modelo sobre Arbitraje Comercial Intemacional de 1985, en su version cnmendada en 2006, A/CN.9/264, en Ley Modelo de la CNUDMI sabre Arbitraje Comercial Internacional 1985 con las enmicndas aprobadas en 2006, p. 30, disponible en hltp://www.uncitral.org/pdf/spanish/lexts/arbitration/ml-arb/07-87001 Ebook.pdf

33. Opción 1, Articulo 7. Definición y forma del acuerdo de arbitraje, (Aprobado por la Comisión en su $39^{\circ}$ periodo de sesiones, celebrado en 2006) 
embargo elimina la innecesaria expresión de "firmado por las partes". Además, amén de expandir y dar un criterio para la interpretación del requisito "escrito", añade un pequeño catálogo, que lejos de pretender ser numeros clausulus, constituye una suerte de vademécum ejemplificativo. El avance más importante es que amplía el sentido tradicional de este concepto al equiparar la forma escrita con todo otro medio "que deje constancia de su contenido en cualquier forma", dejando así la puerta abierta para la existencia de un convenio oral. La segunda opción del artículo en cuestión va mucho más allá y elimina absolutamente todo requisito de forma al consagrar que "[e]l 'acuerdo de arbitraje' es un acuerdo por el que las partes deciden someter a arbitraje todas las controversias o ciertas controversias que hayan surgido o puedan surgir entre ellas respecto de una determinada relación jurídica, contractual o no". Tanto la opción uno como la opción dos del artículo 7 implican un cambio diametral en la orientación de la CNUDMI, pues en ambos casos admite la posibilidad de la celebración de un convenio arbitral oral a condición de que se deje constancia de su contenido. ${ }^{34}$

De igual manera que la Convención de Nueva York en su momento influyó en el desarrollo de las modernas legislaciones,

1) El "acuerdo de arbitraje" es un acuerdo por el que las partes deciden someter a arbitraje todas las controversias o ciertas controversias que hayan surgido o puedan surgir entre ellas respecto de una determinada relación juridica, contractual o no contractual. El acuerdo de arbitraje podrá adoptar la forma de una cláusula compromisoria incluida en un contrato o la forma de un acuerdo independiente,

2) El acuerdo de arbitraje debera constar por escrito.

3) Se entendera que el acuerdo de arbitraje es escrito cuando quede constancia de su contenido en cualquier forma, ya sea que el acuerdo de arbitraje o contrato se haya concertado verbalmente, mediante la ejecución de ciertos actos o por cualquier otro medio.

4) El requisito de que un acucrdo de arbitraje conste por escrito se cumplirá con una comunicación electrónica si la información en clla consignada es accesible para su ulterior consulta. Por "comunicaciön electrónica" se entenderá toda comunicaciỏn que las partes hagan por medio de mensajes de datos. Por "mensaje de datos" se entenderá la información generada, enviada, recibida o archivada por medios electrónicos, magnéticos, ópticos o similares, como pudieran ser, entre otros, el intercambio electrónico de datos, el corrco electrónico, el telegrama, el télex a el telefax.

5) Además, se entenderá que el acuerdo de arbitraje es escrito cuando esté consignado en un intercambio de escritos de demanda y contestación en los que la existencia de un acuerdo sea afi rmada por una parte sin ser negada por la otra.

6) La referencia hecha en un contrato a un documento que contenga una cláusula compromisoria constituye un acucrdo de arbitraje por escrito, sicmpre que dicha referencia implique que esa cláusula forma parte del contrato.

34. CNUDMI, Nota explicativa..., pp. 30, 31. 
Hugo Garcin Larriva

\section{como es de esperarse, los últimos avances y cambios que veni- mos mencionando han sido reflejados también en distintas refor- mas y actualizaciones de orden legislativo que atinadamente han demarcado un nuevo camino en el arbitraje. Dentro de estas podemos encontrar a la peruana35, de la República Dominicana ${ }^{36}$, la chilena ${ }^{37}$, la de Costa Rica ${ }^{38}$, la de Nueva}

35. Ley de Arbitraje de Peni, Decreto Legislativo $N^{\circ} 1071$, Publicado en el Diario Oficial El Peruano el $28 \mathrm{de}$ junio de 2008, Fe de Erratas de fecha 10 de julio del 2008.

Articulo $13^{\circ}$.- Contenido y forma del convenio arbitral.- 1. El convenio arbitral es un acuerdo por el que las partes deciden someter a arbitraje todas las controversias o ciertas controversias que hayan surgido o puedan surgir entre ellas respecto de una determinada relación juridica contractual o de otra naturaleza. 2. El convenio arbitral deberá constar por escrito. Podrá adoptar la forma de una cláusula incluida en un contrato o la forma de un acuerdo independiente. 3. Se entenderá que el convenio arbitral es escrito cuando quede constancia de su contenido en cualquicr forma, ya sea que el acuerdo de arbitraje o contrato se haya concertado mediante la cjecución de ciertos actos o por cualquicr otro medio, 4. Se entendera que el convenio arbitral consta por escrito cuando se cursa una comunicación clectrónica y la información en ella consignada es accesible para su ulterior consulta. Por "comunicaciön electrónica" se entenderí toda comunicación que las partes hagan por medio de mensajes de datos. Por "mensaje de datos" se cnlendera la información generada, cnviada, recibida o archivada por medios electrónicos, magnćticos, ópticos o similares, como pudieran ser, entre otros, el intercambio electrónico de datos, el correo electrónico, el telegrama, el télex o el telefax.5. Se entendera además que el convenio arbitral es escrito cuando esté consignado en un intercambio de escritos de demanda y contestación en los que la existencia de un acucrdo sea afirmada por una parte, sin ser negada por la otra. 6. La referencia hecha en un contrato a un documento que conienga una clausula de arbitraje constituye un convenio arbitral por escrilo, siempre que dicha referencia implique que esa clausula forma parte del contrato. 7. Cuando el arbitraje fucre internacional, el convenio arbitral serí válido y la controversia será susceptible de arbitraje, si cumplen los requisitos establecidos por las normas juridicas elegidas por las partes para regir el convenio arbitral, o por las normas juridicas aplicables al fondo de la controversia, o por el derecho peruano.

36. Ley No. 489.08 sobre Arbitraje Comercial. Publicada en Gaceta Oficial No. 10502, del 30 de diciembre de 2008.

ARTICULO 10.- Definición y Forma de Acuerdo de Arbitraje. I)El "Acuerdo de Arbitraje" es un acuerdo por el cual las partes deciden someler a arbitraje ciertas o todas las controversias que hayan o puedan surgir entre ellas, respecto de una determinada relación juridica, contractual o no contractual. El Acuerdo de Arbitraje podra adoptar la forma de una cláusula arbitral incluida en un contrato o la forma de un acuerdo independiente. 2) El Acuerdo de Arbitraje deberá constar por cserito. Se entenderi que el acuerdo es escrito cuando esté consignado en un documento fimado por las partes o en un intercambio de cartas, faxes, telegramas, corrcos clectrónicos u otros medios de telecomunicación que dejen constancia del acuerdo y sea accesible para su ulterior consulta en soporte clectrónico, óptico o de otro tipo. 3) Se considera incorporado al acuerdo entre las partes el convenio arbitral que consie en un documento al que éstas se laayan remitido en cualquicra de las formas establecidas en el apartado anterior. 4) Se considerará que hay convenio escrito cuando esı́c consignado en un intercambio de escritos de demanda y defensa dentro del proceso arbitral en los cuales la existencia del acuerdo sea afirmada por una parte y no negada por la otra. 5) Cuando el arbitraje fuere internacional, el convenio arbitral será válido y la controversia será susecptible de arbitraje si cumplen los requisitos establecidos por las normas juridicas elegidas por las partes para regir el convenio arbitral. o por las normas juridicas aplicables al fondo de la controversia, o por el derecho dominicano.

37. Ley Num. 19.971. Ministerio de Justicia de Chile Fecha de Publicación, 29 de septiembre de 2004 Articulo $7^{\circ}$.- Definición y forma del acuerdo de arbitraje.

1) El "acuerdo de arbitraje" es un acuerdo por el que las partes deciden someter a arbitraje todas las controversias o ciertas controversias que hayan surgido o puedan surgir entre ellas respec1o de una determinada relación juridica, contractual o no contractual. El acuerdo de arbitruje podrá adoptar 
Partes no siguatarias del convenio arbitrnl:

entre la reulidad conónica y la ficción juridica

\section{Zelandesa ${ }^{39}$, la irlandesa ${ }^{40}$, la de la República de Mauricio ${ }^{41}$, la}

la forma de una cláusula compromisoria incluida en un contrato o la forma de un acuerdo independiente. 2) El acuerdo de arbitraje deberá cunstar por escrito. Se cntenderá que el acuerdo es escrito cuando csté consignado en un documento firmado por las partes o en un intercambio de cartas, télex, telegramas u otros medios de telecomunicación que dejen constancia del acuerdo, o en un intercambio de escritos de demanda y contestación en los que la existencia de un acuerdo sea afirmada por una parte sin ser negada por la otra. La referencia hecha en un contrato a un documento que contiene una cláusula compromisoria constituye acuerdo de arbitraje sicmpre que cl contrato conste por escrito y la referencia implique que esa cláusula forma parte del contrato.

38. Ley sobre Arbitraje Comercial Internacional basada en la Ley Modelo de la Comisión Nacional de las Naciones Unidas para el Derecho Mercantil Intcrnacional (CNUDMi). Publicada en la Gaceta 100 del 25 de mayo de 2011

Articuio 7.-Definición y forma del acuerdo de arbitraje .- 1) El "acucrdo de arbitraje" es un acuerdo por el que las partes deciden someter a arbitraje todas las controversias o ciertas controversias que hayan surgido o puedan surgir entre cllas respecto de una determinada relación juridica, contractual a no contractual. El acuerdo de arbitraje podri adoptar la forma de una cláusula compromisoria incluida en un contrato o la forma de un acuerdo independiente. 2) El acuerdo de arbitraje deberá constar por escrito. 3) Se entenderí que el acuerdo de arbitraje es escrito cuando quede constancia de su contenido en cualquier forma, ya sea que cl acuerdo de arbitraje o contrato se haya concertado verbalmente, mediante la cjecución de ciertos actos o por cualquicr otro medio. 4) El requisito de que un acuerdo de arbitraje conste por escrilo se cumplira con una cumunicaciún electrónica, si la información en clla consignada es accesible para su ulterior consulta. Por "comunicación clectrónica" sc entenderá toda comunicación que las partes hagan por medio de mensajes de datos. Por "mensaje de datos" se cntendera la información generada, enviada, recibida o archivada por medios clectrónicos, magnéticos, úpticos o similares, como pueden ser, entre otros, el intereambio electrúnico de datos, el correo electrónico, el telegrama, el télex o el telefax. 5) Se entendera que el acuerdo de arbitraje es escrito cuando esté consignado $\mathrm{en}$ un intercambio de escritos de demanda y contestación, en los que la existencia de un acuerdo sca afirmada por una parte sin ser negada por la otra. 6) La réferencia hecha en un contrato, a un documento que contenga una clausula compromisoria, constituye un acuerdo de arbitraje por escrito, siempre que dicha referencia implique que esa cliusula forma parte del contrato.

39. Arbitration Act 1996 No 99 (as at 01 January 2011), Public Act, Schedule I Rules applying to arbitration generally. Chapter 2 Arbitration agreement, 7 Form of arbitration agreement (1) An arbitration agreement may be made orally or in writing. Subject to section 11, an arbitration agreement may be in the form of an arbitration clause in a contract or in the form of a separale agrecment. (2) A reference in a contract to a document containing an arbitration clause constitutes an arbitration agreement. provided that the reference is such as to make that clause part of the contract.

40. Arbitration Act 2010, PART 2. Arbitration. Adoption of Model Law.

6. - Subject to this Act, the Model Law siball have the force of law in the State and shall apply to arbitrations under arbitration agreements conecrning -- (a) international commercial arbitrations, or (b) arbitrations which are not international commercial arbitrations.

Disponible en http://www irishstatutcbook. ie $2010 \mathrm{en} / \mathrm{act}$ pub/000!/index.html

41. INTERNATIONAL ARBITRATION ACT 2008.

PART II - INITIATION OF PROCEEDINGS 4. Arbitration agreement (1) An arbitration agreement - (a) may be in the form of an arbitration clause in a contract or other legal instrument or in the form of a separate agreement; and (b) shall be in writing. (2) An arbitration agreement is in writing where - (a) its contents are recorded in any form, whether or not the arbitration agrecenent or the contract has been concluded orally, by conduct, or by other means; (b) it is concluded by an electronic communication and the information contained in it is accessible so as to be usable for subsequent reference; or (c) it is contained in an exchange of statenents of elaim and defence in which the existence of an agreement is alleged by one party and not denied by the ofher. (3) The reference in a contract to a document containing an arbitration clause constitules an arbitration agreement in writing where the reference is such as to make that clause part of the contract.

Disponible en hutp//www.wipo.int/wipolex/es/text.jsp'?lile_id=189487 
de Eslovena ${ }^{42}$, la escocesa ${ }^{43}$, la de Inglaterra y Gales ${ }^{44}$, la alemana ${ }^{45}$, la de Estados Unidos ${ }^{46}$, así como también en el nuevo proyecto de Ley de Arbitraje para el Ecuador preparada por CESAR CORONEL JONES ${ }^{47}$, donde en el artículo 11 opta por el texto literal de la opción uno de la Ley Modelo CNUDMI 2006.

Es evidente que todas estas decisiones, apreciaciones doctrinales y reformas legislativas han construido una interpretación -cada vez creciente-sobre la naturaleza que debe tener el requi-

42. CODE OF CIVIL PROCEDURE (Official Gazette of the Republic of Slovenia, No. 26/99)

\section{Article 461}

An arbitration agreement may be concluded in relation to a particular dispute, as well as in relation to future disputes which may arise from a particular legal relationship. An arbitration agreement shall be valid only if made in writing. An arbitration agreement is also made in writing if made by the exchange of letters, eables, telex messages or other means of telecommunications, which can provide a written record of its conclusion. An arbitration agreement shall be deemed to have been made in writing also by the exchange of a statement of claim, in which the claimant alleges the existence of such agreement, and a statement of defense, in which the respondent fails to deny this allegation. Disponible en hltp://www.sloarbitration.org/english/slo-arb-law/code-civil-procedure-vscbina.html

43. Arbitration (Scotland) Act 2010 4. Arbitration agrecment

An "arbitration agreement" is an agreement to submit a present or future dispute to arbitration (including any agreement which provides for arbitration in accordance with arbitration provisions contained in a separate document).

Disponible en hup://www.legislation.gov.uk/asp/2010/1/contents

44. England and Wales Arbitration Act 1996 The arbitration agreement 6 Definition of arbitration agreement.

(1) In this Part an "arbitration agrecment" means an agreement to submit to arbitration present or future disputes (whether they are contractual or not). (2)The reference in an agreement to a written form of arbitration clause or to a document containing an arbitration clause constitutes an arbitration agrecment if the reference is such as to make that clause part of the agreement.

Disponible en http://www.legislation.gov.uk/ukpga/1996/23

45. Ley Alemana de Arbitraje 98, Libro X del Código de Procedimiento Civil

Articulo 1029 Definición.- L. El "acuerdo de arbitraje" es un acucrdo celcbrado por las partes para someter a arbitraje todas o una parte de los puntos litigiosos presentes o futuros con respecto de una relación juridica, ya sea contractual, ya sea de otra naturaleza. 2.- El acuerdo de arbitraje puede cons. tar en un documento separado ("cl acuerdo de atbitraje separado") o en una cláusula contractual ("la clàusula de arbitraje").

Disponible en latip://www.dis-arb.de/en/51/malerials/ley-alemana-de-arbitraje-98-id5

46. UNIFORM ARBITRATION ACT, SECTION 6. VALIDITY OF AGREEMENT TO ARBITRATE

(a) An agreement contained in a record to submit to arbitration any existing or subsequent controversy arising between the partics to the agreement is valid, enforceable, and irrevocable except upon a ground that exists at law or in equity for the revocation of a contract. http://www.law.upenn. cdu/bll/archives/ulc/uarba/arbitrat1213.htm

47. Césnr Coronel Jonts, Presente y futuro del Arbitraje Comercial en el Ecuador: Hacia una nucva ley, en Revista Ecuatoriana de Arbitrajc, Instituto Ecuatoriano de Arbitraje y Editorial Juridica Cevallos, Quito. 2010, pp. 402, 403. Es de nuestra opinión que si la nueva Ley de arbitraje que se plantea para el Ecuador piensa incomorar los mayores avanees en materia arbitral, asi como constituirse de cierta manera en un nuevo referente de avanee legislativo a nivel regional -como en su momento ha sido fa peruana-, se deberia dar el salto completo y optar por ta opción dos del convenio arbitral que prevé la Ley Modelo CNUDMI. 
sito de escrituración del convenio arbitral. Al parecer la mayoría de la legislación y doctrina actual, así como de los precedentes arbitrales -podríamos estar ante el surgimiento de un posible estándar mínimo consuetudinario sobre este requisito-, apuntan a que la escrituración del convenio arbitral ha dejado de ser concebido como un requisito ad solemnitaten del convenio arbitral y se relaciona mas con un requisito ad probationem ${ }^{48}$. Este fenómeno de haber mutado de un requisito de la esencia del negocio jurídico a un requisito de prueba del mismo se debe a dos principales factores $^{49}$ (i) a un esfuerzo por priorizar la realidad de las cosas sobre las formalidades a las que el derecho se suele apegar muchas veces para esterilizar los efectos jurídicos de los contratos y de los convenios arbitrales, en particular en el marco del tráfico comercial y en el desarrollo de las inversiones, y (ii) porque la naturaleza ad probationem contribuye mejor a la eficacia del arbitraje y a la inevitabilidad de sus consecuencias que constituyen la vigas maestras para la consolidación del sistema arbitral.

En el sistema arbitral ecuatoriano se ha dicho y resuelto muy poco al respecto. Hasta la terminación del presente trabajo no hemos encontrado ningún pronunciamiento de las cortes nacionales sobre la materia. Sin embargo hemos podido identificar algunos precedentes arbitrales que con objeto del presente estudio se analizan ${ }^{50}$ y que nos llevan a la conclusión que nuestros árbitros -si bien no son muchos debido a que tampoco se presentan mayores casos sobre esta materia-, lejos de estar ajenos y contrarios a estos avances, son bastante permeables y acuciosos al momento de decidir su competencia en tratándose de estos temas. Esto no debería recurrir mayor sorpresa pues, la mayoría del foro ecuatoriano que trata el tema concluye que el requisito de escrituración previsto en los artículos 5 y 6 de la

48. Fernando Cantuarias Salavierry y Roque J. Caivano, La nueva lcy de arbitrajo peruana: un nucio salto a la modernidad, en Revista Peruana De Arbitraje, No. 7, 2008, Lima, p. 58; y JorGt: SANTISTEvan Di: Noriegn, Inevitabilidad del arbitraje ante la nuesa key pertana, en Revista Peruana De Arbitraje, No. 7, 2008, Lima, p. 99.

49. Jorgi: Santistlivan de Noriega, Extensión..., p. 22.

50. Ver infra $\S 8$. 
LAM constituyen solemnidades ad probntionem ${ }^{51}$, que, como lo es ya común para la doctrina internacional, pretende basar el análisis sobre la existencia del consentimiento más que sobre la existencia de tal o cual forma ${ }^{52}$.

\section{Consecuencia negocial del arbitraje: LA RELATIVIDAD DE LOS EFECTOS FRENTE A LOS TERCEROS}

Como ya lo hemos anunciado en el acápite anterior, el arbitraje tiene como presupuesto un negocio jurídico conocido como convenio arbitral. Esto implica necesariamente que, de conformidad con su naturaleza, le es aplicable la teoría general del negocio jurídico. El negocio jurídico entendido como una norma jurídica ${ }^{53}$ que vive dentro de un espacio limitado por la autonomía de la voluntad de las partes ${ }^{54}$-como presupuesto de hecho establecido por el ordenamiento jurídico- despliega un ámbito material, temporal, espacial y personal 55 .

El ámbito material se refiere al objeto mismo del negocio jurídico - la creación o extinción de obligaciones- que estará asociado directamente con su posibilidad y licitud. El ámbito temporal del negocio jurídico hace referencia al lapso de tiempo

51. Ai EANDRO PONCE MARTINEZ A, Notas sobre la clausula compromisoria y sus efectos en fa legislación ecuatoriana, en Roque J. CAIVANo, La Cláusula ..., p. 434; Ernesto SAlcedo Verduga, El arbitraje Justicia Altemativa, Distrilib, Guayaquil, 2007, p. 1II. Arneando Serrano Puig, La autonomia..... p.559. En contrario Dirgo Pérez, Ornónez, El convenio arbitral en la legislación ecuatoriana, en Tratado de Derecho Arbitral: El Convenio Arbitral, Tomo I, Pontificia Universidad Javeriana, Grupo Editorial Ibảĩez, Instituto Peruano de Arbitraje, Bogotá, 2011, p. 513.

52. Francisco GonzAlez DE Cossio, La nueva forma del acuerdo arbitral: otra victoria del conscensualismo, en Arbitraje Comercial y Arbitraje de Inversión, Tomo 1: "El arbitraje en el Perú y el mundo", Instituto Peruano de Arbitraje, Lima, 2008, p. 217.

53. Este categorizaciön deviene de la facultad nommativa que reviste el negocio juridico. Es justamente este contenido normativo asociado con la facultad de configuración interna del negocio como expresión de la voluntad de los individuos lo que en esencia constituye el elemento sustancial del negocio juridico. Carlos Maluouer de Motes. Derecho de la persona y negocio juridico, Ed. Bosch, Barcelona, 1993, pp. 232-234.

54. Emilıo Berti, Teoria general del Negocio Juridico, Ed. Revista de Derecho Privado, Madrid, 1959, pp. 45-5I. Luigt FerRI, Lecciones sobre el contrato: Curso de Derecho Civil, Ed. Andrés Bello, 2006, pp. 44-47, Guillermo Ospina Fernindez; Enuardo Ostina Acosta, Tcoria General..., pp. 312-317, Fernando Vidal RAmirtz, El acto juridico, Ed. Gaccta Juridica, Lima, 2007, pp 38-40.

55. Rafafl Rojna Villegas, Compendio de Derecho Civil, Tomo III, Ed. Portúa, México, 1999, pp. 14()$-149$. 
dentro del cual el negocio jurídico está llamado a producir sus efectos que será determinado por un plazo, condición, o por el cumplimiento propio de los efectos que está llamado a producir -o el incumplimiento de los mismos cuando deben necesariamente producirse en una determinada temporalidad asociada a la naturaleza de la prestación-. El ámbito espacial implica la determinación geográfica donde el negocio jurídico despliega sus efectos. Esta determinación territorial reviste suma importancia pues incidirá directamente sobre la legislación aplicable al negocio jurídico. Por último, pero no menos importante, se encuentra el ámbito personal. El ámbito personal implica la definición de a quién le son oponibles los efectos del negocio jurídico. Esto es un fiel reflejo de la exégesis del negocio. Siendo el negocio jurídico esencialmente una manifestación de la voluntad de una persona con el fin y la intención de producir los efectos jurídicos que el ordenamiento jurídico le reconoce, es lógico que este contenido normativo del negocio jurídico vincule única $y$ exclusivamente a quienes, en uso de sus atribuciones, han consentido libre y voluntariamente en él. Es en esencia este ámbito personal del negocio jurídico del cual se desprende el principio de relatividad de los efectos del negocio jurídico que in genere establece que los negocios jurídicos producen efectos únicamente entre las partes.

En el Ecuador no existe en la legislación positiva una norma que consagre de manera expresa este principio ${ }^{56}$, sin embargo, se ha reconocido que el mencionado principio está incorporado en nuestro ordenamiento jurídico a través del artículo 1561 del Códico $\mathrm{CIVIL}^{57}$ (CC) que establece "[t]odo contrato legalmente celebrado es una ley para los contratantes, y no puede ser invalidadoo sino por su consentimiento mutuo o por causas legales".

56. Algunas legislaciones traen reconocimiento expreso de esta tendencia, verbi gracias, el articulo 1363 del Código Civil peruano establece "Los contratos solo producen efectos entre las partes que los otorgan y sus herederos..."; el articulo 1275 del Código Civil de España que en igual sentido establece "los contratos sólo producen efectos entre las partes y sus herederos..."; el artículo 1199 del Código Civil de Argentina que en la misma linea reza "los contratos no pueden oponerse a terceros ni ser invocados por ellos".

57. Codificación 10, Registro Oficial Suplemento 46 de 24 de junio del 2005. 
Es en este contexto que, al ser el convenio arbitral un negocio jurídico, esté delimitado por el principio de relatividad de los efectos jurídicos del mismo, lo cual significa, por un lado (i) que solo las partes intervinientes en el mismo se vean afectadas por sus efectos, y por otro (ii) que ese negocio jurídico es oponible erga omnes, en el sentido de que todo aquel que es absolutamente tercero a la relación jurídica debe respetarla. Por lo tanto una persona ajena a la misma no puede entorpecer, entrometerse ni impedir la realización plena de los efectos que el negocio jurídico está llamado a producir. En consecuencia solo las partes están llamadas a arbitrar -sea como actor o demandado- una vez surgido el conflicto, y por el otro lado, ningún tercero -en especial los jueces- puede desconocer los efectos de un convenio arbitral válidamente celebrado, por lo que deben abstenerse de inmiscuirse en el proceso arbitral.

Ahora si bien el tema de la relatividad absoluta del negocio frente a terceros resulta ser un tema relativamente claro, no lo es el tema de la determinación de quienes sí son llamados al encuentro del negocio como partes del mismo. Las partes de un negocio jurídico, en principio, son los mismos sujetos que lo celebraron ${ }^{58}$, pero resulta que puede ser que los celebrantes lo hayan hecho como representantes, agentes o mandatarios de otra persona, o que en virtud de otro negocio $u$ hecho jurídico una persona pase a ocupar el lugar que otra tuvo en la primera relación, o bien sea que otra persona haya manifestado su consentimiento con el negocio jurídico a través de un medio distinto a la suscripción del mismo. No es raro que una empresa utilice una maraña de subsidiarias para el cumplimiento de un contrato para uno o varios beneficiarios, o que una compañía utilice a otra para la celebración de un contrato con el único fin de evadir responsabilidades, que varias partes celebren contratos coligados dependientes unos de otros por encadenamientos, y que solo uno o alguno de ellos no posea convenio arbitral, entre otros casos. Estas interrogantes trasladadas al campo que nos cita en el presente ensayo, nos llevan a cuestionarnos sobre el hecho de 58. Fernando Vidal. Ramirez, El acto juridico. Ed. Gaceta Juridica, Lima, 2007. p. 243. 
Partes no signatarias del convenio arbitral: entre la ralidad económica y la ficción jurídica

la posibilidad de incluir en un arbitraje a otras personas que no hayan sido los celebrantes originarios del convenio arbitral. Claro está, con la presente salvedad enunciada en un principio, este "no suscriptor" tiene que ser catalogado como parte del negocio jurídico, pues si del examen que se realice se llega a la indefectible conclusión de que es un simple y llano tercero absoluto, la discusión al parecer se ha de terminar con un simple no. Entonces como se podrá advertir la clave para la resolución de este dilema constituye el determinar quiénes son considerados como partes dentro del convenio arbitral.

\section{ACerCamiento a UNA delimitación de las paR- TES NEGOCIALES}

Como hemos establecido en el acápite anterior, normalmente las partes dentro de un negocio jurídico son sus celebrantes originarios -aquellos que concibieron y dieron a luz al mismo-. Sin embargo, como también hemos anotado esto no siempre se compadece con la realidad, especialmente en la complejidad del mundo comercial y de inversiones, donde es más frecuente el uso de vehículos de inversión como sociedades constituidas bajo la figura de subsidiarias, la estructuración de grupos económicos que actúan como una sola realidad a pesar que tener una multiplicidad de entidades jurídicas, de figuras societarias para disfrazar o proteger a los verdaderos interesados en el negocio, etcétera. Es por esto importante intentar esbozar en este punto un acercamiento a quién puede ser considerado como parte.

Comencemos enunciando un precepto que puede sonar a perogrullada, parte no es sinónimo de persona. En efecto el artículo 1454 de nuestro $\mathrm{CC}$ establece que "[c]ada parte puede ser una o muchas personas". Por lo tanto parte no es específicamente toda persona que concurre a la celebración del contrato sino, como sostiene MESSINEO59, solamente aquellas que configuran el

59. Citado por Luis Strgio Parraguez Ruiz, Cuarto.... p. 245. 
"centro de intereses del negocio", el cual comúnmente se encuentra formado por una persona, sin embargo de que pueden formarlo dos o más que busquen la consecución de un mismo interés, caso en el cual nos encontramos frente a una parte compleja o compuesta ${ }^{60}$. En esta línea, para LARROZA parte es "la persona o conjunto de personas con un interés comín, que se interrelacionan entre sí y establecen las relaciones jurídicas que surgen del contrato"61.

Estos sujetos que conforman el núcleo del interés negocial pueden ostentar dos calidades: (i) parte formal y (ii) parte sustancial ${ }^{62}$. La parte formal se puede definir como aquella que concurre a expresar su voluntad en la celebración del negocio jurídico; mientas que parte sustancial puede ser definida como aquella que es titular de los intereses negociales que constituyen la relación jurídica. Como podrá advertirse, lo normal es que en una parte confluyan las dos calidades, sin embargo de lo cual, como también podrá dilucidarse, puede ocurrir lo contrario y que estas calidades se encuentren disociadas. En el caso de que un sujeto ostente únicamente la calidad de parte formal -como en el caso del representante de una compañía- este no es una verdadera parte en el sentido que hemos venido analizando; caso contrario, cuando una parte ostenta la calidad de parte sustancial exclusivamente -como en el caso de la compañía representada-, ésta sí se constituye en una parte real como titular del interés negocial, pues es en ella en quien se han de afincar los efectos jurídicos del negocio como si hubiese intervenido directamente. Esta hipótesis no reviste de mayor problema, sin embargo no es la única que se puede plantear. Puede ser que en el ámbito de un negocio jurídico exista una persona, que sin haber actuado a través de un mandatario o representante, se constituya en parte integral del centro de interés del negocio jurídico a través de la manifestación de su voluntad de manera tácita -de ser expresa no acarrearía mayores problemas-, de

60. Ibidcm, p. 245.

61. Citado por Luis Sergio Parraguez Ruiz, Cuarto.... p. 245.

62. Ibidem, $\mathrm{p}$ 
suerte que al parecer resulta vinculada y obligada a través del negocio jurídico. Pareciese claro que a toda luz estos actos mediante los cuales expresa su voluntad le configuran como una parte sustancial del negocio jurídico -verdadera parte-; sin embargo, cabe la disquisición -sin mayor relevancia pragmática63 - de si confluye o no la categoría de parte formal, toda vez que en sentido restringido parte formal es aquella que concurre a manifestar su voluntad en la celebración del negocio jurídico -que pareciese no aplicar-, y en sentido amplio es aquella que expresa de una u otra forma su voluntad que le vincula al negocio jurídico -que podría ser aplicable-, discusión por lo demás inoficiosa pues lo verdaderamente importante es su categorización como parte sustancial.

Cómo podemos evidenciar entonces la problemática queda al fin reducida a la búsqueda esencial del consentimiento ${ }^{64}$ de una parte que vinculen sus actuaciones con el centro de interés del negocio jurídico. Por lo que, en resumen, la respuesta a la pregunta de quién se encuentra obligado por el convenio arbitral constituirá un examen de los hechos del caso para determinar quien se encuentra en el centro de los intereses del negocio jurídico a través de la declaración de su voluntad, y quién no.

\section{EXTENSIÓN DE LOS EFECTOS DEL CONVENIO ARBI- TRAL A TERCEROS: INFERENCIA DE LA VOLUNTAD}

Del hilo conductor que venimos exponiendo podemos decir que en resumen la respuesta a la pregunta de quién se encuentra

63. No porque el tema de diferenciar una parte sustancial de una formal no revista de importancia, sino porque at ser catalogado como parte sustancial -verdadera parte-, para efectos de oponerle las disposiciones del negocio juridico, no importa si fue parte formal o no del negocio.

64. El consentimiento de una parte puede ser expreso o bien tácito. En el caso de consentimiento tácito se busca inferir el mismo a través de actos conducentes que vincule al sujeto con el interés negocial. El silencio en la mayoria de casos no implica manifestación del consentimiento normalmente, salvo que de los hechos que rodeen al silencio se pueda inferir que dicho acio implique aceptación -p. c. "de no rechazar esta proforma en 24 horas se entenderá aceptada", en este caso las parles le han dado un valor positivo al silencio-. Para mayor abundamiento en el tema ver Gulllermo OsPiNA Flrnindez; Eduardo Ospina Acosta. Teuria Gencral.... pp. 185-190; Fernando Vidal. Ramirez. El acto..., pp. 93-102; Luis Sergio Parragutz Rutz. Cuarto.... pp. 157-170. 
obligado por el convenio arbitral constituirá un examen de los hechos del caso para determinar quién se encuentra en el centro de los intereses del negocio jurídico a través de la declaración de su voluntad, y quién no, independientemente de si ha suscrito o no el acuerdo de arbitraje ${ }^{65}$, pues al ser partes sustanciales están poderosamente vinculados al negocio jurídico en torno al cual se ha pactado el mismo66, dado que el mero hecho de no haberlo firmado no le excluye necesariamente de los efectos que de este se generen ${ }^{67}$.

Es arduo y difícil para los tribunales arbitrales, pero esencial, que se examine si es que de los actos realizados por la parte constituyen o no una derivación del consentimiento en los términos que hemos analizado. Se puede derivar el consentimiento a pesar de que no exista en estricto sensu una oferta y una aceptación de conformidad con los términos generalmente referidos para los negocios jurídicos, aún a pesar de que las actuaciones de la "parte" carezcan de una naturaleza recepticia ${ }^{68}$, o en otras palabras, que no se hayan planteado en el sentido de encaminarlas hacia las otras partes del acuerdo arbitral con el fin de obtener de ellas una manifestación. En este sentido en el caso HerCules InC v. United States se estableció que "la existencia del consentimiento para obligarse con un contrato puede inferirse a través de las conductas de las partes"69.

Como se apreciará nuevamente, el ejercicio consistente en derivar la voluntad para la determinación y caracterización de

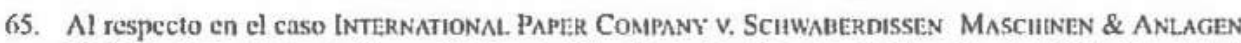
GMBH, Corte de Apelaciones del Cuarto Circuito de los Estados Unidos, No. 98-2482, March 14, 2000 la Corte sostuvo "una parte puede consentir someterse a arbitraje por medios diferentes de la firma puesta en el instrumento que contiene la cláusula arbitral".

66. Jorge Santistevan de Noriega. Extensión.... p. 32: Ropue J. Caivano, Arbitraje y grupos ..., p. 123

67. Roque J. CaIVano, Arbitraje $y$ grapos ...., p. 124.

68. AlFriado Bull.ard GonzAlez, ¿Y quiénes cstán invitados a la Ficsta?: La incorporación de pancs no signatarias al arbitraje $y$ el articulo $14 \mathrm{de}$ la $\mathrm{ky}$ de arbitraje peruana, en Tratado de Derecho Arbitral El Convenio Arbitral, Tomo II, Pontificia Universidad Javeriana, Grupo Editorial tbảñez, Instituto Peruano de Arbitraje, Bogotá. 2011. p. 717.

69. Hercules InC v. United States, Corte Suprema de Justicia de los Estados Unidos, 516 U.S. 417 424, 116 S.Ct. 981, 987, 134 L.Ed.2d 47, 1996. En el mismo sentido ver Fisstek v. INTERNATIONAI. BANK, Corte de Apelaciones del Segundo Circuito de los Estados Unidos, 282 F.2d 231, 233, 2d Cir. 1960; Sunkist Sort Drinks Inc v. Sunkist Growers Inc, Corte de Apelaciones del Décimo Primer Circuito de los Estados Unidos, 10 F.3d 753, 756-57, 1 It th Circ., 1993. 
un sujeto como parte de un convenio arbitral vinculándolo al centro de intereses del negocio jurídico, implica determinar, como sostiene ORREGo VicUÑA ${ }^{70}$, ante todo cuál es el interés real que debe vincularse mediante acuerdo de arbitraje, lo que significa en definitiva identificar la realidad económica subyacente a la relación contractual. Simultáneamente deberá determinarse, si acaso ese interés debe prevalecer sobre "ficciones jurídicas" que se originan en cuestiones como la personalidad jurídica de las sociedades, la nacionalidad, independencia contractual y otras. Ya sea que la conclusión sea favorable a la extensión o contraria a la misma, siempre será esa realidad económica la que determinará si ella se justifica, pues será esta realidad económica la que constituye fnctn concudentin que nos permitirá derivar el consentimiento de una parte.

Ahora, puede pensarse que esta voluntad inferida de la parte no signataria es insuficiente con respecto al requisito de forma escrita del convenio arbitral. Al parecer resulta, a primera vista, de lo más lógico inferir que el requisito de escrituración jamás puede ser suplido por actos que no contengan un sustrato de esta naturaleza. Al respecto, debemos regresar a la interpretación debida de este requisito en el sentido en que, como tal, se exige un indicio de prueba por escrito de la existencia del convenio arbitral -cuando así es requerido ${ }^{71}$, mas no se requiere que las partes manifiesten su consentimiento con el mismo en forma escrita -como se exigía antes la firma de las partes en el convenio arbitral. Es decir el requisito de un sustrato escrito es exigible para la prueba de la existencia del acuerdo arbitral, más no es exigible un consentimiento por escrito a la parte que pretende vinculársele. En efecto, un grupo de cortes en importantes jurisdicciones han sostenido que tan solo el acuerdo arbitral en sí mismo requiere de escrituración, mientras el ámbito de aplicación subjetivo y material es una cuestión que ha de ser resuelta

70. Francesco Orrego Vicusa, La extension de la cläusula de arbitraje a terceros: Realidades cconómicas y ficciones juridicas, en Tratado de Derecho Arbitral. El Convenio Arbitral. Tomo I, Pontificia Universidad Javeriana, Grupo Editorial ibaiñcz, Instituto Pcruano de Arbitraje. Bogrotả, 2011, pp. 363. 364.

71. Recordemos que la tendencia moderna y creciente es la de abandonar el requisito de escrituracion. 
como parte de los méritos del caso ${ }^{72}$. Todo lo anterior es plenamente coincidente con lo que se ha venido enunciando en el presente trabajo pues en ningún caso se plantea la exclusión el grado necesario de expresión de voluntad para que una parte no signataria consienta en el arbitraje, pues, consecuentemente con la naturaleza flexible del arbitraje, con la interpretación ad probationem que debe revestir la forma escrita en el acuerdo arbitral y la necesidad de darle eficacia al arbitraje, éste exige un cuidadoso análisis de los hechos y de todas las circunstancias que rodean al caso, así como de las conductas desarrolladas por las partes involucradas que permitan descubrir consentimientos implícitos por parte de los no signatarios ${ }^{73}$.

Cabe mencionar que no todos los tribunales arbitrales admiten que el convenio arbitral pueda ser extendido a partes no signatarias, sea por falta de prueba de la vinculación real ${ }^{74}$-como ya hemos dicho el estándar de prueba es sumamente alto-, o porque simplemente consideran que al amparo de la lex arbitrii no procede la extensión del acuerdo arbitral75, o sea porque de

72. Nonit Rubins, Arbitration ..., p. 543. Ver además la nota 28 del presente articulo donde se enumeran algunas jurisprudencias en este sentido.

73. Jorge Santistevan de Noriega, Extcnsión..., p. 41.

74. Caso CCl no. 6519. Collection of ICC Awards, 1991 - 1995, Ed. Kluwer Law International, pp. 420 y ss.

"si se hubiese probado que estuvieron representadas de manera efectiva o implicita o que jugaron un papel activo en las negociaciones que le precedieron o están implicadas de manera directa en el contrato que contiene la cláusula arbitral"

75. Caparo Grotp ltd v. Fagor Arrastate Sociedad Cooptrativa, Corte Comercial, Qucen's Bench Division, 7 de agosio de 1998 citado en Rogue J. Calvano, Arbitraje y grupos ..., p. 137 "bajo los heclıos del presente caso, la posición resulta clara. El contrato, como lo he dicho, está gobemado por la ley inglesa; de igual manera el acuerdo arbitral. Al amparo de la ley inglesa, no veo fundamento bajo el cual se pueda sostener que las partes, tanto del contrato como del acuerdo arbitral, eran otras que Fargo por un lado y CML por el otro. En mi juicio no hay cabida para una conclusión que incorpore a CAPARO como parte del contrato ni del convenio arbitral". Caso paradigmático es PEttrson Farmis Inc v. C\&M Faraing LTD, Corte Suprema Inglesa, EWHC, 121, Comm., 4 de febrero de 2004 donde se resuelve que la doctrina del grupo de sociedades no es parte del dereclro inglés. Un extenso análisis del caso se puede encontrar en NoAl Rtains, Arbitration ... Pp. 548-551. Decisión DF LA CORTE dE CASACIÓN Holanidesa citado por NoAH Ruiuns, Arbitration ... p. 556 "bajo la legislación holandesa, soio una transferencia formal de derechos (como la cesión, subrogación, o la asunción de una deuda) pucde resultar en vinculante a un no signatario de un convenio arbitral". DLcistón DE LA Corte Distrital de Moscủ en el caso IMP Grotr (Ciapre) V. Atroimi, Yearbook of Commercial Arbitration, XXIII (1998). pp. 745-749 citado por Noalr RuBıns, Arbitration ... , p. 556, "El ténnino "acuerdo por escrito" debe incluir a un acuerdo arbitral en un contrato o a un acuerdo arbitral, fimado por las partes o contenido en el intertambio de cartas o tclegramas... El consentimicnto oral o tácito no logra la conclusión de un acucrdo arbitral". 
plano rechazan la posibilidad de que una parte no signataria del convenio arbitral sea incluida en un proceso de esta naturaleza ${ }^{76}$ -como actor o demandado-.

Ahora bien, como venimos planteando durante todo el presente ensayo, la extensión de los efectos del convenio arbitral a terceros es un caso sumamente complejo de configurar, por lo cual los tribunales no debieran considerar la situación de sujetos que no hayan suscrito el acuerdo de arbitraje -yendo más allá de la personalidad societaria por ejemplo- a menos que ello se demostrase como razonable ${ }^{77}$ en base a indicios suficientes para considerar a priori como una posible parte. Pero que podemos considerar como barómetro para lo razonable o no. Es aquí donde surge como elemento integrador y de escrutinio el principio de buena fe.

\section{EXTENSIÓN DE LOS EFECTOS DEL CONVENIO ARBI- TRAL A TERCEROS: EL PRINCIPIO DE BUENA FE}

El principio de buena fe constituye uno de los pilares sobre los cuales se construye la lex mercatoria ${ }^{78}$, y ha sido reconocido por la generalidad de los ordenamientos jurídicos del orbe. En amplio sensu el principio de buena fe conlleva un actuar ético de

76. Caso Basf argentina SA v. Capdevielle Kay y Cin SA, CSJN, 11/05/2004, Competencia No 1651 , XXXIX, Lexis-Nexis on line, No. 35000740, citado en Roque J. Canvano, Arbitraje y grupos ...,p. 121, reconociendo que aunque intervino en la celebración, firmó los instrumentos que contiene la cláusula arbitral y cjecutó el contrato " [el convenio arbitral] claramente está referida a la intervención del órgano arbitral para la solución de diferendos que surjan entre vendedor y comprador, pero no entre el corredor y su comitente enajenante, los que discrepan en torno al resultado de la gestión del primero y la debida rendición de cuentas sobre los supuestos importes recibidos de los compradores"

77. Francisco Orrego Vicuna, La extensión.... p. 376.

78. Un cjemplo de esto es la disposición del articuio l(7) de los Princirios Unidrott sobre los contraTOS INTERNACIONALES que establece "(1) Las pares deben actuar con buena fe y lealtad negocial en el eomercio internacional. (2) Las partes no pueden excluir ni limitar este deber." Otro cjemplo que nos aporta el mismo instrumento es el referido en cl articulo 4 (8) (c) al incluir al principio de buena fe y lealtad negocial como factores de la integración de un contrato. Otra referencia de suma importancia que realizan estos principios es al establecer que el principio de buena fe y lealtad negocial constituyen fuentes de las obligaciones implicitas a un contrato - articulo $5(1)(2)(\mathrm{c})$ - De igual manera al regular el cumplimiento o incumplimiento de una determinada condición, su alcgación se condiciona a una actuación de buena fe y lealtad negocial de las partes-articulos $5(3)(3), 5(3)(4)$.- 
los individuos que participan en la negociación, celebración, ejecución, terminación y liquidación de un negocio jurídico. En este sentido podemos asimilar al principio de buena fe con la ética negocial. La Corte Suprema de Justicia de Colombia ha sostenido al respecto:

"La expresión "buena fe" (bona fides) indica que las personas deben celebrar sus negocios, cumplir sus obligaciones $y$, en general, emplear con los demás una conducta leal. La lealtad en el Derecho se desdobla en dos direcciones: primeramente, cada persona tiene el deber de emplear para con los demás una conducta leal, una conducta ajustada a las exigencias del decoro social; en segundo término, cada cual tiene el derecho de esperar de los demás esa misma lealtad. Trátase de una lealtad (o buena fe) activa, si consideramos la manera de obrar para con los demás, y de una lealtad pasiva, si consideramos el derecho que cada cual tiene de confiar en que los demás obren con nosotros decorosamente."79

Ahora como bien sabemos la buena fe puede encarnar dos dimensiones: una buena fe en sentido subjetivo y una buena fe en sentido objetivo. En materia negocial no se exige una buena fe en sentido subjetivo, pues esta se relaciona con las convicciones y el fuero interno de los sujetos, la buena fe que se requiere en materia negocial es la buena fe en sentido objetivo. Esta categoría de ética negocial implica una apreciación de la conducta de los sujetos desde la óptica de lo socialmente exigible ${ }^{80}$. Este tipo de conductas -sostiene MEDIAN ALCOZ ${ }^{81}$ - deben apegarse a un estándar de coherencia exigible, que conlleva un juicio comparativo entre la conducta precedente y la conducta sucesiva con un resultado lógico de generación de una confianza razonable. Si el resultado de la aplicación del estándar de coherencia es otro, estamos entonces ante un quebrantamiento del deber de buena fe y lealtad negocial.

79. Sentencia de 23 de junio de 1958. G.J. T. LXXXVIII, pág. 233. En Código Civil comentado, Ed. Leyer, 15. edición, Bogota 2006, pág 1031. Citada en Citado por Luis Sergio Parraguez Ruz, Cuarto....p. 37.

80. LuIS Sirgio Parraguzz RUiz, Cuarto....p. 37

81. Maria MtDina Atcoz, Responsabilidad precontractual cstudio accrca de la ruptura injustificada de los tratos preliminares, Forum, 2006, p. 3. 
Partes no signatarins del convenio arbitral: entre la realidad econóntica y la ficción juridica

Este principio de buena fe tiene variopintas aplicaciones dentro del derecho como son en la integración de los contratos, la responsabilidad precontractual y la culpa in contraendo, en la apreciación del cumplimiento de las obligaciones, la teoría de la imprevisión, la ineficacia de la alegación del dolo propio, la doctrina de los actos propios entre otros. Como es de suponerse este principio no es ajeno al desarrollo del arbitraje y, por ejemplo, se manifiesta con fuerza en los principios de inevitabilidad del arbitraje, presunción de eficacia, in dubio pro arbitrii, etcétera. Tratándose del tema que nos convoca el principio de buena fe resulta de suma importancia.

La inferencia del consentimiento de una parte no signataria con respecto del negocio principal y su correspondiente convenio arbitral halla su basamento claro en al menos dos aplicaciones del principio de buena fe y lealtad negocial como lo hemos delimitado, es decir aplicando el test general del estándar de coherencia. Por un lado la prohibición de contradecir los actos propios, pues desde que un sujeto ejecuta actos propios de una parte o interviene de manera que expresa su aceptación con el contenido del contrato y del convenio arbitral, optar por el disenso sería una clara contradicción con lo actuado por el mismo sujeto, lo que daría como resultado un defraudamiento de la confianza razonable; por otro lado, la interpretación de los contratos conforme a los dictados de la buena fe, es decir, auscultando la verdadera y real intensión de las partes de conformidad con lo que verosímilmente ellas entendieron, pudieron entender o debieron entender, obrando con cuidado y previsión de conformidad con el grado de diligencia debido que cada una estaba llamada a emplear, pues de esta interpretación podríamos abstraer la generación o no de un estándar de confianza razonable. De allí que, como dice CaIvano,

"cuando la conducta de las partes permita inferir una declaración tácita de voluntad, subordinar sus efectos a la forma escrita o a la existencia de una manifestación expresa del consentimiento, implicaría admitir la violación al princi- 
pio de la buena fe que rige el derecho de las obligaciones, y una tolerancia indebida a la mala fe y a la deslealtad en los negocios jurídicos" 82 .

Este planteamiento ha sido recogido por distintos tribunales arbitrales que frecuentemente han lidiado con esta problemática. En los casos CCI No. 7604 y 7610 los tribunales sostuvieron que es viable

"[l]a extensión de los efectos jurídicos de un acuerdo arbitral a un tercero no-signatario, cuando las circunstancias del negocio en cuestión demuestren la existencia de una voluntad común de las partes en el proceso, de considerar a ese tercero como involucrado en una forma considerable o como una verdadera parte en el contrato que contiene la cláusula arbitral, o cuando las circunstancias permiten presumir que ese tercero aceptó el sometimiento a ese contrato especialmente si lo reconoció expresamente" 83 .

\section{EXTENSIÓN DE LOS EFECTOS DEL CONVENIO ARBI- TRAL A TERCEROS: APROXIMACIÓN A LAS APLICACIO- NES CONCRETAS}

Como podemos observar la (i) inferencia del consentimiento y (ii) la aplicación del principio de buena fe, han llevado a que los distintos tribunales arbitrales desarrollen un crisol de figuras que, cumpliendo con estos requisitos tan complejos, desembocan en la extensión de efectos jurídicos a partes no signatarias. De suma importancia han sido dos casos paradigmáticos que han generado un vademécum de posibilidades, nos referimos a los casos Dow Chemical v. Isover Saint Gobain ${ }^{84}$-que inauguró

82. Roque J. Caivano, Arbirraje y grupos ...., p. 143.

83. Laudos CCI No. 7604 y 7610 , Collection of ICC Awards, 1996-2000, Ed. Kluwer Law International, pp. 510 y $5 s$.

84. Dow Cilemical v. Isover Saint Gobain, Laudo interino de 23 de septiembre de 1982, Collection of ICC, 1974-1985. Kluwer Law International. pp. 151 y ss. Arbitros Bertiotd Golddan, MiCiAet. VASSEUR Y Pieter SANSERS 
la teoría del grupo de sociedades- y THOMSON - CSF S.A.C. v. AMERICAN ARBITRATION ASSOCIATION ${ }^{85}$-donde se establecen cinco de las teorías más importantes en la materia, a saber: incorporación por referencia, asunción de obligaciones, relación de agencia, razgamiento del velo societario/Alter ego, estoppel-. Otro puntal importante ha sido la jurisprudencia marcada por las cortes francesas, la cuales han sido proclives a recibirlas de manera decisiva estas teorías, marcando un derrotero favorable dentro de las cortes nacionales.

Sin pretender agotar ni hacer un tratamiento exhaustivo de las distintas figuras que hemos anunciado, haremos un breve repaso de cada una de ellas.

\subsection{El grupo de sociedades}

La teoría del grupo de sociedades parte, básicamente, de una consideración de orden económico muy importante. Estamos frente al caso en que una sociedad celebra uno o varios contratos con otra, incluyendo en éste un convenio arbitral. Una de ellas es parte integral de un grupo de compañías. La compañía contratante y sus hermanas -filiales, casa matriz, o subsidiaria- participan de manera determinante en la ejecución del contrato de manera tal que las partes signatarias del contrato reconocen la participación activa de éstas en la misma. La pregunta en este caso es, ¿puede una de las compañías no signatarias ser parte del proceso arbitral? La respuesta al amparo de la teoría del grupo de sociedades es afirmativa siempre y cuando estas hayan actuado como una misma realidad económica -como una sola parte frente a la otra- y que las partes hayan entendido que éstas eran parte activa del contrato. Al respecto SANTISTEVAN DE NORIEGA establece que esta doctrina

"se ha sustentado en tres elementos: (i) el consentimiento al arbitraje derivado del conocimiento de la existencia del

85. Tionison - CSF S.A.C. v. AMERICAN Arimtration ASSOCIATION, Corte de Apelaciones del Segundo Circuito de Estados Unidos, 64 f. 3d 773, 776, 2 cir. 1995. 
convenio arbitral y de sus alcances; unido a (ii) la conducta decisiva que desarrollan los no signatarios en la vida contractual que justifica su participación en el arbitraje; y (iii) los dos elementos anteriores tomados conjuntamente que permiten identificar a tales no firmantes como partes no signatarias y no como terceros ajenos al contrato" ${ }^{\prime 86}$.

Por ser el caso Dow Chemical v. Isover Saint Gobain el paradigmático al respecto, creemos pertinente citar la resolución del tribunal arbitral:

"la cláusula arbitral expresamente aceptada por determinadas sociedades del grupo económico debe obligar a las otras que, en virtud del rol que les cupo en la celebración, ejecución o rescisión de los contratos que contienen la cláusula arbitral y de acuerdo a la común intención de todas las partes del juicio arbitral, parecen haber sido verdaderas partes en los contratos o estuvieron ampliamente comprometidas en ellos y en los conflictos que de ellos surgieron" ${ }^{87}$

\subsection{Incorporación por referencia}

Nos encontramos frente a la presencia de contratos coligados, uno que incluye un convenio arbitral, y otro que careciendo de acuerdo de arbitraje, hace referencia al contrato que si lo tiene. La condición para la aplicación de esta teoría es que la interdependencia de los contratos sea de tal manera que estos constituyan una unidad económica indisoluble.

86. Santistevan de Noriega, Extensión...., p. 37

87. En cl mismo sentido Laudo CCI No. 5103 Collection of ICC Awards, 1996-2000, Ed. Kluwer Law International, pp. 361 y ss, "Se cumplen las condiciones que flevan a reconocer la unidad de grupo cconómico, ya que todas las sociedades que lo componen tienen la misma participación, tanto real como aparente, en una relación contractual internacional compleja, en la cual los intereses del grupo prevalecen por sobre el de cada una de ellas. La seguridad de las relaciones cconómicas internacionales exige que se tome en cuenta esa realidad económica y que todas las socicdades del grupo respondan conjunta y solidariamente por las deudas de las que ellas, directa o indirectamente, sacaron provecho". 


\subsection{Asunción de obligaciones (Assumption)}

Esta teoría básicamente se basa en que, siendo una parte no signataria de un negocio jurídico continente de un convenio arbitral, esta sume las obligaciones que devienen del mismo y procede a su ejecución. En este sentido, se debe entender que una parte que asume las obligaciones de un contrato consiente de suyo en el arbitraje contenido en el mismo, contrario sensu implicaría un defraudamiento a la buena fe y consecuente inevitabilidad del arbitraje.

\subsection{Relación de agencia (Agency)}

Cuando los signatarios y los no signatarios existe una relación de representación -inclusive mandato sin representaciónde la cual se puede inferir que la participación de los signatarios vincula activamente a los no signatarios dentro del negocio, convirtiéndoles en los verdaderos titulares de los intereses que conforman el centro de la relación económica-jurídica subyacente al negocio jurídico.

\subsection{Rasgamiento del velo societario o teoría del alter ego}

A diferencia de la doctrina del grupo de sociedades, en el presente caso no se analiza el comportamiento de las compañías pertenecientes al grupo en función de inferir su consentimiento de conformidad con las actuaciones de ellas como una sola realidad económica. Mas bien nos encontramos ante el fenómeno en el cual una parte no signataria utiliza a un signatario como un simple vehículo para la relación mercantil. Normalmente, esta doctrina tiene aplicación en las relaciones compañía matrizcompañía subsidiaria, cuando una de ellas pretende escapar de los efectos del negocio jurídico subyacente a través de la comparecencia única de la otra. 
Como podrá inferirse la casuística podría ser interminable, pero podemos ir delineando algunos requisitos que matizan la viabilidad de la procedencia de esta teoría. CAIVANO ${ }^{88}$ establece algunos indicios que deben probarse para la aplicación de la teoría del alter ego los cuales son: (a) gran infra-capitalización de la sociedad en el momento de su formación y durante su vida; (b) incumplimiento de formalidades propias de las sociedades, tales como carecer o superposición de gerentes o directores, empleados, de archivos o registros, o no pagar dividendos; (c) desvíos de fondos de la subsidiaria hacia la matriz o sus accionistas; (d) cuando reconocer la personalidad diferenciada puede violar el orden público o proteger a alguien de responsabilidad criminal; (e) confusión de patrimonios; (f) Conductas o circunstancias que impliquen un virtual abandono de la separación de sus identidades societarias como oficinas y números de teléfono comunes, no tener cuentas bancarias, ni papelería, no realizar transacciones ni tener actividad; (g) el grado de discrecionalidad que muestra la sociedad controlante, cuando está bajo el control de otra a tal punto que ambas constituyen un único emprendimiento; $y$, (h) cuando es una mera pantalla o un alter ego de la controlante.

\subsection{Doctrina de los actos propios (Estoppel)}

Este es el caso de aplicación del principio de buena fe más claro. Cuando un sujeto en virtud de su propia conducta en relación al negocio jurídico -conducta previa y sucesivas-genera en la otra parte una confianza razonable de considerarle parte del contrato, conlleva a que el no signatario está impedido de oponerse a su inclusión en el arbitraje. Caso contrario implicaría un

defraudamiento del estándar de coherencia y correspondiente violación del principio de buena fe.

AlfREDO BUllard grafica esta doctrina desde la siguiente perspectiva:

88. Rogue J. Caivano. Arbitrije y grupos .... pp. 133-134. 
Partes no signatarias del convenio arbilral:

entre la realidad económicn y la ficción jurílica

"Ello ocurre solo cuando (1) la mano derecha y la izquierda pertenecen al mismo centro de imputación (identidad de sujetos); (2) lo que la mano derecha ha hecho anteriormente permite derivar con claridad que la mano izquierda se encuentra obligada posteriormente a conducirse de la misma manera (carácter vinculante de la conducta original); y (3) efectivamente la mano izquierda está haciendo algo incompatible con lo que hizo la mano derecha (contradicción entre la conducta original y la conducta posterior)" 89

La jurisprudencia tampoco ha sido ajena a estos preceptos. En el caso jaguar la CORTE dE APELACIONES dE PARís sostuvo que

"[e]n el derecho del arbitraje internacional, los efectos de la cláusula compromisoria se extienden a las partes directamente implicadas en la ejecución del contrato desde el momento en que sus situaciones y sus actividades hacen presumir que éstas tenían conocimiento de la existencia y del alcance de esta cláusula, con el fin de que el árbitro pueda ser competente respecto de todos los aspectos económicos y jurídicos del litigio"90

\subsection{Cesión de derechos y obligaciones y de posición con- tractual (Assigment)}

Esta doctrina no devela mayor misterio. Quien se incorpora a un contrato mediante cesión -sea de derechos y obligaciones o de posición contractual- se entiende consentir con el convenio arbitral aunque no haya sido signatario del mismo, salvo que del análisis del contrato de cesión se desprenda clara y expresamente que las partes querían desembarazarse de la obligación de arbitrar. Inclinarse por lo contrario sería minar el principio de inevitabilidad del arbitraje.

89. Alfredo Bullard GonzÁlez, ¿ Y quicines.... r. 724.

90. Caso Jaguar, Corte de apelación de Paris, cilado por Merino Mercian p. 1289, en el mismo sentido los casos de la Corte de Apelación de Paris Societé Ofer Brotuers v. THe Tokio Marine and Fire Insurance: Co., Elf Aquitane v, Grupo Orri, Citados por Rogue J. Caivano, Arbitraje y grupos ..., pp. 127, 127 


\subsection{Promesa por un tercero y estipulación a favor de un ter- cero (Third party beneficiary)}

Estamos presentes frente a la fenomenología en la cual una parte signataria de un negocio jurídico pretende derivar derechos o afincar obligaciones frente a un tercero que no ha sido signatario del negocio jurídico. Es claro que si no media consentimiento del no signatario con respecto de aceptar esas consecuencias jurídicas no se vería vinculado por las mismas. En el caso que se pueda inferir su consentimiento conforme al principio de buena fe, el tercero necesariamente tiene que verse vinculado a su vez con el convenio arbitral contenido en el negocio principal y puede ser involucrado en el procedimiento arbitral.

\section{Extensión del Convenio Arbitral a partes no SIGNATARIAS: PRÁCTICA ECUATORIANA}

Lejos de ser una fenomenología ajena a nuestra realidad, el foro ecuatoriano se ha visto avocado a enfrentar estos dilemas sin apoyo de una jurisprudencia de las cortes nacionales, estudios en la materia y sobre todo con el gran inconveniente -a veces prácticamente imposible- que supone el acceso a precedentes arbitrales en nuestro sistema. En este ensayo pretendemos exponer algunos casos identificados que pueden ir guiándonos con respecto a esta materia.

En el caso 075-08 tramitado ante el CENTRO DE ARBITRAJE Y MEDIACIÓN DE LA CÁMARA DE COMERCIO DE QUITO (CAM CCQ) ${ }^{91}$ que versaba sobre un contrato de publicidad, el actor -la compañía de publicidad- demandó a la compañía contratante y además a la compañía madre del grupo pese a que ésta no era signataria del convenio arbitral. Los demandados eran dos compañías pertenecientes a un grupo económico que poseía varias

91. Caso 075-08 CAM CCQ, Acta de Audiencin de Sustanciación de 20 de marzo de 2009, Laudo final 21 de septiembre de 2009, Árbitro Único doctor Galo Galarza Paz. 
empresas relacionadas. Para su declaratoria de competencia el tribunal analiza algunos hechos que, aduce el actor, confluyen en el hecho de que la compañía signataria era un alter ego de su matriz, la cual había venido actuando como verdadera parte reconociendo su vinculación contractual -doctrina de los actos propios-. Los hechos determinantes que consideró a priori el tribunal para sustentar su decisión fueron el que la compañía matriz poseía el $100 \%$ de las acciones de la compañía subsidiaria, que las facturas y pagos correspondientes se los establecía entre la matriz y la actora y no a través de la compañía signataria, que la subsidiaria se disolvió de oficio - dos años después de la firma del contrato- conforme resolución de la Superintendencia de Compañías, aunque la misma había sido inscrita en el Registro Mercantil, ni tampoco había entrado en proceso de liquidación conforme lo ordenado por el Órgano controlador, y por último el que la matriz ejerce las mismas actividades que la subsidiaria en otros locales de la ciudad. La resolución de competencia del tribunal arbitral fue la siguiente:

Este Tribunal para resolver sobre su propia competencia, conforme lo dispone al Art. 22 de la Ley de Arbitraje y Mediación, considera: a) La actora "CompañIfa A S.A.", por medio de su Gerente y Representante Legal señor " $X$ " deduce su demanda en contra de dos personas jurídicas distintas "COMPAÑIA B S.A." y "Compañta C S.A.", esto es, en la relación jurídico procesal planteada hay pluralidad de sujetos pasivos, a quienes la actora exige juntamente, en forma expresa y simultánea, el pago de la totalidad de prestaciones específicas, que al decir de esta son obligaciones solidarias que las compañías demandadas le están adeudando. La solidaridad la fundamenta en lo previsto en el Art. 17 de la Ley de Compañías, según se establece en la demanda; b) Es incuestionable que la compañía demandada ComPAÑIA B S.A. en la cláusula compromisoria ha sometido al Tribunal Arbitral la dirimencia de las controversias emanadas de la ejecución del Contrato en que se apoya la demanda. Es también verdad que, ni de la cláusula compromisoria ni de ningún otro documento aparece que la otra demandada compañía COMPAÑIA C S.A. se haya sometido a la jurisdicción arbi- 
tral de la Cámara de Comercio de Quito. Desde este punto de vista, se tendría que la competencia para conocer las pretensiones de Compañía B S.A. pertenece al Tribunal Arbitral y la competencia para conocer las pretensiones en contra de Compañia C S.A. pertenece al Juez de lo Civil. Pero dada la solidaridad, conexión y complementariedad que en la demanda se formula la reclamación en contra de COMPAÑIA B S.A. y Compañia C S.A. no pueden haber dos procesos ni órganos jurisdiccionales distintos para conocer el caso. Tiene que ser uno mismo. El problema se presenta en dilucidar: ¿A cuál de los dos órganos jurisdiccionales le toca conocer la controversia? No al juez ordinario, por el efecto negativo establecido expresamente en el primer apartado del Art. 7 de la Ley de Arbitraje y Mediación, que dice: "El convenio arbitral que obliga a las partes a acatar el laudo que se expida, impide someter el caso a la justicin ordinaria ...". Eliminado, por el efecto jurídico mencionado, el Juez de lo Civil, le toca al órgano Arbitral asumir dicha competencia. La resolución sobre la competencia por cierto se limita a los asuntos concernientes a la relación jurídico procesal. No significa, bajo ningún aspecto, aceptación o no de la existencia de relaciones jurídicas sustanciales o materiales entre la actora y cada una de las compañías demandadas ${ }^{92}$. Este es un asunto de fondo que se resolverá en el laudo arbitral de acuerdo con las normas jurídicas y los méritos procesales, particularmente del análisis y valoración de los medios de prueba que se aporten al proceso".

Dentro de su laudo el tribunal también hizo precisiones con respecto a la doctrina del levantamiento del velo societario. El árbitro sostuvo:

"Para el levantamiento del velo de una sociedad anónima, como en el caso subjudice que nos ocupa, deben cumplirse copulativamente los siguientes presupuestos: 1. Que se haya

92. Es importante resaltar este razonamiento def tribunal arbitral, pues indiea que la declaración de competencia incluyendo a la parte no signataria, no implica la acep̧ación de la responsabilidad de ésta en el incumplimiento demandado - cuestiòn de fondo- sino simplemente el que existen hechos suficientes que al tribunal ie generan la convicción de ser competente para conocer el proceso arbitral en contra de los demandados -cuestion de competencia y jurisdicción-. 
Partes no siguatarias del comvenio arbitral:

cutre in realidad económica y la ficcion juridica

constituida una sociedad anónima, observando todos los requisitos puntuales exigidas para el efecto por la Ley de Compañias, hasta su inscripción en el Registro Mercantil; 2. Que esa creación haya sido con la finalidad de utilizar a la compañía anónima en actividades dolosas o, en otros términos, que el dolo producido sea consecuencia directa de la presencia de la compañía anónima como agente facilitador del mismo; y, 3. Que uno o más de los socios o accionistas de la compañía sea el agente ejecutor y beneficiario del dolo."

\section{Y agregó:}

"Según la doctrina, con la que concuerda este Tribunal, para la configuración del dolo se requiere lo siguiente: a) Que haya existido una conducta de los agentes dirigida a engañar a quien resulta victima del mismo, consistente en astucias, artificios, maquinaciones (animus dicendi); obviamente no habrá engaño si la supuesta víctima colabora o hubiese conocido esa conducta de los agentes...b) Que haya un efectivo daño o perjuicio pecuniario. El daño o perjuicio es elemento primordial del acto doloso. Si faltare este sería inoficioso exigir los otros elementos que configuran el dolo. Si no se produce daño no se genera responsabilidad civil alguna."

Como se apercibe el árbitro establece un estándar de prueba extremadamente alto para establecer el levantamiento del velo societario, pues como sostuvo en su laudo "la generalización o aplicación indebida del levantamiento del velo societario conllevaría graves consecuencias negativas, como las de inseguridad jurídica, la deformación de la institución de la sociedad anónima $y$ un medio eficaz para ahuyentar a los interesados en aportar, como accionistas, sus capitales para esa clase de sociedades. A más de abrir la puerta para que todo acreedor que considere que no puede satisfacer su acreencia con el patrimonio social de una compañía acuda al levantamiento del velo societario para exigir que el pago de sus pretensiones se haga con el patrimonio de alguno de los accionistas solventes". El tribunal al final en el laudo, y luego de practicada la prueba, decidió desechar las pre- 
tensiones de la demanda por que en el transcurso del arbitraje se aportaron medios probatorios que fueron desvirtuando los indicios que el tribunal estimó en su momento oportunos para declararse competente.

En otro caso tramitado ante el CAM CCQ93 la COMPAÑía E presentó una demanda en contra de un grupo de demandados, estos al contestar la demanda reconvienen tanto a la COMPAÑIA E como a su representante legal por sus propios y personales derechos. Éste al contestar la reconvención no planteó excepción de incompetencia del tribunal arbitral ni tampoco inexistencia del convenio arbitral. El tribunal arbitral al declararse competente sostuvo:

"Sin embargo en el contrato referido no es parte el "SEÑOR $\mathrm{X}^{\prime \prime}$, por lo cual, este convenio arbitral no le obligaría, por no haberlo suscrito.- Empero el mencionado "SEÑOR X", al ser reconvenido personalmente por los demandados [nombres de todos los demandados], contesta, por medio de su abogado, Dr. "Y", a título personal, sin oponer la excepción expresa de incompetencia del Tribunal Arbitral o la ausencia de cláusula compromisoria a dar ninguna otra indicación acerca de su renuencia a que la reconvención planteada en su contra sea decidida por arbitraje, lo que determina que existe voluntad expresa tanto de los demandados que reconvienen como de quien replica la reconvención, SEÑOR $X$, de someter la controversia a arbitraje, en los términos del Art. 6 de la Ley de Arbitraje y Mediación"94

En otro procedimiento arbitral95 seguido en el CENTRO DE ARbitRaje Y MEDIACIÓN DE AMCHAM QuITo (CAM AMCHAM)

93. CAso 026-05 CAM CCQ. Acta de Audiencia de Sustanciación de 21 de octubre de 2005, Laudo de 21 de agosto de 2006, Laudo ampliatorio de 4 de septiembre de 2006, Árbitro Único, doctor Alejandro Ponce Martinez.

94. En contrario Armando Serrano Puig, Lat autonomía .... p. 558, que al referirse al consentimiento tácito en arbitraje sostiene "es aquel que se produce en un intercambio de escritos de demanda y contestación en los que la existencia de un acuerdo sea afirmada por una parte sin ser negada por otra, sistema del que nuestra ley se apartó,"

95. CAso 01-11 CAM AMCHAM. Acta de Audiencia de Sustanciación final de 10 de encro de 2012. Tribunal Arbitral, doclores Alejandro Ponce Martinez - presidente- Luis Parraguez Ruiz, Juan Carlos Solines Moreno. 
la COMPAÑía $F$ demandó a los SEÑORES " $Y$ " $Y$ " $Z$ ", pese a que " $Z$ " no era parte signataria del convenio arbitral. El contrato había sido firmado por " $Y$ " a nombre y en representación de una presunta sociedad de hecho. Al contestar la demanda se opuso la excepción de incompetencia del tribunal arbitral con respecto de " $Z$ " por no haber sido signatario del convenio arbitral. Previo a su competencia el tribunal arbitral celebró algunas audiencias con el fin de que las partes alegasen sobre la competencia respectiva del tribunal. Como resultado de este ejercicio el tribunal estimó que encuentra indicios suficientes que, de manera a prio$r i$, le llevan a generar una convicción suficiente para considerar que " $Z$ " había realizado actos ratificatorios que al parecer le vinculan de manera decisiva como parte del negocio jurídico origen del procedimiento arbitral. En este caso nuevamente el tribunal salvó esta decisión estableciendo que es una decisión sobre competencia aclarando que no implica su vinculación y responsabilidad final sobre las alegaciones imputadas en la demanda, pues esto es de decisión del laudo final.

\section{El CONVENIO ARBITRAL Y LOS VERDADEROS TERCEROS}

Como podrán apreciar a lo largo del presente trabajo, la extensión de los efectos a partes no signatarias es un escenario de tal compleja configuración y difícil planteamiento que realmente constituye un caso de excepciones casi previsto para laboratorio. En este sentido hay que tener mucho cuidado porque más de una vez una parte puede verse tentada a intentar incoar un arbitraje contra un tercero bastante cercano al negocio pero que no ha sido parte en el sentido en el cual definimos en este trabajo. Muchas veces este instinto casi irresistible, aupado por estar frente a un tercero que tiene intereses -sea por beneficio o perjuicio- en los resultados del arbitraje, y que de haber sido un proceso ordinario hubiese contado con los mecanismos adecuados para hacer valer sus derechos, nos lleva a equivocadas conclusiones y a forzar los presupuestos aquí enunciados ${ }^{96}$. 
Como sostiene Bullard esta teoría se "aleja por lo tanto de una concepción procesal según la cual se pueden incorporar terceros a un proceso arbitral como si se tratara de la jurisdicción ordinaria"97, y continúa, "por la naturaleza contractual del arbitraje no es posible acudir a mecanismos como los usados en los códigos procesales que admiten la participación de terceros cuyos intereses puedan verse afectados por la sentencia"98. En sentido contrario la CORTE CONSTITUCIONAL COLOMBIANA admitió que las partes al suscribir un convenio arbitral habían habilitado al tribunal arbitral para que resolviera ese conflicto específico por lo que era admisible la intervención de terceros en el proceso que tuvieran interés y legitimidad para participar en el arbitraje ${ }^{99}$.

En el caso de nulidad Hidrotoapi EP v. CONSTRuctura NORBERTO ODEBRECHT SA ${ }^{100}$ la presidenta de la Corte Provincial de Pichincha, al resolver sobre la participación en el proceso de nulidad de una parte del arbitraje que no presentó la acción resolvió 101 "la tercería de cualquier clase que sea, pude ser propuesta solo(sic) en juicios ordinarios o en juicios ejecutivos, ya que al ser un incidente, como así ha sido calificada normativamente la tercería, no es compatible con la esencia del procedimiento arbitral ni con la acción que nos ocupa". Si bien el fundamento por el cual resuelve excluir a la parte de la acción no es el que hemos planteado, nos sirve para aclarar el panorama con

96. Al respecto y como hemos venido planteando durante todo el ensayo, José MrRINo MerCilín Y José: Cijl lón Merina -José Merino Mercilán y Josét Cillóón Menina, Tratado de Derecho Arbitral, Ed. Civitas. Navarra, 2006, p. 1288- establece que "el principio res inter alios acta brilla aqui cn todo su esplendor. En consecuencia, no puede plantearse un proceso arbitral respecto de quicnes no han sido parte en la convención de arbitraje*

97. Alfrt.do Bullard Gonzillez, ¿Y quiénes..., p. 712.

98. Ibidcm, p. 716.

99. Citado por Santistivan dE NORiega, Extensión... p.34. En sentido contrario podemos encontrar el caso de ENERgia Elftctrica ne Bogoth v. Estruco LtDa. - Laudo de is de agosto de 1964 Citado por SANTISTEVAn de NoriegA, Extensión... p.33-donde la pretensión por parte de la referida socicdad de vincular a una compañia aseguradora fue rechazada por entenderse que cra un ente ajeno al contrato constituyendo un terecro arbitral que no estaba legitimado para una intervención litisconsorcial o de coadyuvancia.

100. Sentencia de la Presidencia de la Corte Provincial de Justicia de Pichincha, Quito, 29 de marzo de 2011, Dra. Isabel Ulloa Villavicencio, Presidenta.

101. En el presente caso la acción de nulidad fue presentada por la Procuraduria General del Estado y no por Hidrotoapi EP. En el transcurso del caso Hidrotoapi EP prelendió ser considerado como tercero interesado de la acción de nulidad, siendo rechazado por la Presidenta de la Corte. 
Partes no sigualarias del conventio arbitral:

entre la realidad económica y la ficción juridica

respecto a la admisibilidad de las tercerías en un proceso arbitral o no.

\section{ACCIÓN DE NULIDAD Y EXTENSIÓN DE LOS EFECTOS DEL CONVENIO ARBITRAL A TERCEROS}

Como sabemos la acción de nulidad de los laudos arbitrales en nuestro sistema constituye un mecanismo extraordinario de impugnación de los actos procesales. Como característica fundamental de esta acción podemos decir que se concibe como un mecanismo de control judicial del procedimiento arbitral102, por lo tanto no constituye un mecanismo de alzada o de apelación del fondo del laudo arbitral que permita a las cortes la reconsideración de las decisiones de los árbitros ${ }^{103}$. La segunda característica que configura esta acción es el de ser numerus clausualus ${ }^{104}$, es decir que es una acción constreñida única y exclusivamente a las causales mencionadas por el artículo 31 de la LAM, de lo cual se desprende que no se puede entablar una acción de nulidad contra un laudo por una causal distinta. Estas causales son:

a) No se haya citado legalmente con la demanda y el juicio se ha seguido y terminado en rebeldía. Será preciso que la falta de citación haya impedido que el demandado deduzca sus excepciones o haga valer sus derechos $y_{\text {, }}$ además, que el demandado reclame por tal omisión al tiempo de intervenir en la controversia;

b) No se haya notificado a una de las partes con las providencias del tribunal y este hecho impida o limite el derecho de defensa de la parte;

102. Jr. Security Cia. Lida. vs. Productos Avon del Ecuador S.A., Sentencia de la Presidencia de la Corte Provincial de Pichincha, 30 de junio de 2010; Empresa Pública Hidrotoapi E.P. vs. Construtora Norberto Odebrecht, 20 de marzo de 2011: Primax Comercial del Ecuador S.A. vs. Lafarge Cementos S.A., 26 de abril de 2011.

103. Latin American Telccom Inc. vs. Pacificte! S.A., Corte Suprema de Justicia, Decisión No. 242-2007, 11 de julio de 2007, R.O. Suplemento 542, 6 de marzo 2009.

104. Taminternacional Cia. Lida. vs. Fernando Albornoz, Sentencia de la Presidencia de la Corte Pravincial de Pichincha, 31 de marzo de 2010; Cuerpo de Ingenicros del Ejército vs. Hidrotambo, Sentencia de la Presidencia de la Corte Provincial de Pichincha, 15 de noviembre de 2011. 
c) Cuando no se hubiere convocado, no se hubiere notificado la convocatoria, o luego de convocada no se hubiere practicado las pruebas, a pesar de la existencia de hechos que deban justificarse;

d) El laudo se refiera a cuestiones no sometidas al arbitraje o conceda más allá de lo reclamado; 0 ,

e) Cuando se hayan violado los procedimientos previstos por esta Ley o por las partes para designar árbitros o constituir el tribunal arbitral.

Como puede observarse, de las causales enunciadas, no se desprende que bajo alguna de ellas sea posible cobijar una acción de nulidad en virtud de que los árbitros de manera motivada consideren a un sujeto como parte no signataria dentro del proceso arbitral, y decidan efectivamente extenderle sus efectos sea como actor o demandado. Esto sucede básicamente porque nuestra legislación es muy proclive a blindar la decisión de competencia de los árbitros, dejando que ellos sean los únicos competentes para determinar su propia competencia en lo que se conoce como el principio kompetenz - kompetenz.

\section{A MANera de CONClusión}

Como se ha podido observar durante el desarrollo del presente trabajo, las complicaciones que el arbitraje debe enfrentar en la actualidad con respecto a la complejidad del mundo comercial actual, son varias y de más frecuentes. Lejos de ser realidades ajenas al foro ecuatoriano -no se puede pretender que seamos una isla-, son casos que con inusitada repetición tienen que enfrentar tanto abogados como árbitros nacionales. La fenomenología atrás de estos casos es muy rica, sin embargo, como ha sido el objetivo del presente trabajo, podemos abstraer un germen base para la construcción de una doctrina general en la materia. Podemos decir entonces que es factible que un tribunal arbitral extienda los efectos de un convenio arbitral a una parte 
no signataria cuando (i) se pueda inferir de manera inequívoca el consentimiento de la parte no signataria con respecto del negocio jurídico; y que, (ii) si el no extender los efectos del convenio arbitral a la parte no signataria de como resultado una vulneración al principio de buena fe. Sin embargo, cabe ser enfático en que esta teoría es de aplicación excepcional y requiere, necesariamente, de un estándar extremadamente elevado de prueba, por lo que su configuración debe envolver una complejidad tal, que garantice que ningún tercero verdadero sea inmiscuido en un proceso arbitral con el cual no tiene ningún vínculo jurídico económico real. 